\title{
Metastatic Prostate Cancer Cells Secrete Methylglyoxal-Derived MG-H1 to Reprogram Human Osteoblasts into a Dedifferentiated, Malignant-like Phenotype: A Possible Novel Player in Prostate Cancer Bone Metastases
}

\author{
Cinzia Antognelli ${ }^{1, *(\mathbb{D}}$, Lorella Marinucci ${ }^{1}$, Roberta Frosini ${ }^{1}$, Lara Macchioni ${ }^{2}{ }^{\circledR}$ and Vincenzo Nicola Talesa ${ }^{1}$ \\ 1 Department of Medicine and Surgery, Bioscience and Medical Embryology Division, University of Perugia, \\ L. Severi Square, 06129 Perugia, Italy; lorella.marinucci@unipg.it (L.M.); roberta.frosini@unipg.it (R.F.); \\ vincenzo.talesa@unipg.it (V.N.T.) \\ 2 Department of Medicine and Surgery, Biochemistry and Physiology Division, University of Perugia, \\ L. Severi Square, 06129 Perugia, Italy; lara.macchioni@unipg.it \\ * Correspondence: cinzia.antognelli@unipg.it; Tel.: +39-075-585-8354
}

Citation: Antognelli, C.; Marinucci, L.; Frosini, R.; Macchioni, L.; Talesa, V.N. Metastatic Prostate Cancer Cells Secrete Methylglyoxal-Derived MG-H1 to Reprogram Human Osteoblasts into a Dedifferentiated, Malignant-like Phenotype: A Possible Novel Player in Prostate Cancer Bone Metastases. Int. J. Mol. Sci. 2021, 22, 10191. https://doi.org/10.3390/ ijms221910191

Academic Editor: Noemí Eiró

Received: 23 August 2021

Accepted: 16 September 2021

Published: 22 September 2021

Publisher's Note: MDPI stays neutral with regard to jurisdictional claims in published maps and institutional affiliations.

Copyright: (c) 2021 by the authors. Licensee MDPI, Basel, Switzerland. This article is an open access article distributed under the terms and conditions of the Creative Commons Attribution (CC BY) license (https:// creativecommons.org/licenses/by/ $4.0 /)$.
Abstract: Bone metastases from prostate cancer (PCa) result from a complex cross-talk between PCa cells and osteoblasts (OB). Thus, targeting this interplay has become an attractive strategy to interfere with PCa bone dissemination. The agents currently used in clinical trials have proved ineffective, boosting research to identify additional mechanisms that may be involved in this two-directional talk. Here, we investigated whether and how 5-hydro-5-methylimidazolone (MG-H1), a specific methylglyoxal (MG)-derived advanced glycation end product (AGE), was a novel player in the dialogue between PCa and OB to drive PCa bone metastases. Conditioned medium from osteotropic PC3 PCa cells, pre-treated or not with a specific MG scavenger, was administrated to human primary $\mathrm{OB}$ and cell morphology, mesenchymal trans-differentiation, pro-osteogenic determinants, $\mathrm{PCa}-$ specific molecules, and migration/invasion were studied by phase-contrast microscopy, real-time PCR, western blot and specific assays, respectively. We found that PC3 cells were able to release MG-H1 that, by binding to the receptor for AGEs (RAGE) on OB, reprogrammed them into a less-differentiate phenotype, endowed with some PCa-specific molecular features and malignant properties, in a mechanism involving reactive oxidative species (ROS) production and NF-kB pathway activation. These findings provide novel insights into the mechanisms of PCa osteoblastic metastases and foster in vivo research toward new therapeutic strategies interfering with PCa/OB cross-talk.

Keywords: methylglyoxal; prostate cancer; bone metastases; osteoblasts; ROS; RAGE; NF-kB

\section{Introduction}

Metastasis, responsible for most cancer deaths, is a complex and multi-step process during which primary cancer cells acquire migratory abilities, enter and survive in the bloodstream, and then reach, by extravasation, a secondary metastatic site where they start proliferating [1]. It is now widely accepted that a pivotal role in the onset of metastasis is played by the interaction between cancer cells and the stromal resident cells at the metastatic site [2]. According to the "seed and soil" theory by Paget, both cancer and tumor microenvironment (TME)-associated cells necessitate gaining novel and specific characteristics with the aim of creating suitable signaling networks to initiate a metastatic outgrowth [3]. An ideal "soil" for cancer cell metastasis is the bone. In fact, it represents a rich source of different chemokines, growth factors, and cytokines that facilitate cancer cell growth and colonization in addition to sustain their survival [4]. In particular, the cells of the bone participating in bone remodeling, namely osteoblasts (OB) and osteoclasts, are essential for cancer cell homing to and seeding in bone, cancer cell re-activation, macro- 
metastatic lesion growth, all these ultimately leading to extensive tumor cell colonization to bone [5].

Among the solid tumors that preferentially metastasize to the bone, there is prostate cancer (PCa). In this ambit, $\mathrm{PCa}$ is somewhat unique in its tendency to produce osteoblastic lesions [2,5]. Interestingly, these lesions are made of hypermineralized bone due to OB hyperactivity. However, since this process occurs abnormally, it results in a structure with a markedly reduced mechanical strength and, consequently, more susceptible to painful pathological fractures [6], which implies a diminished quality of life of the patients. In accordance with the general theory of Paget, also PCa cells are able to settle and grow in the skeleton due to cross-talk between the bone microenvironment and tumor cells [7]. In particular, bone provides chemotactic, adhesion, and growth factors that allow PCa cells to target and proliferate in the skeleton [8]. Reciprocally, PCa cells can produce factors that interfere with the physiological activity of bone cells and modulate bone remodeling [5], or even express OB-related genes, a condition known as "osteomimicry" [1,9]. Building on this evidence, targeting the cross-talk between PCa and bone cells has become an attractive strategy to interfere with PCa bone metastasis, and, indeed, several agents are currently in clinical trials to combat bone-metastatic PCa [5,6]. Unfortunately, these therapies have failed in showing prolonged median progression-free survival or overall survival [10-12]. Hence, focusing the research on understanding additional mechanisms and molecules through which PCa and bone cells realize their cross-talk to nurture the lethal phenotype of bone-metastatic $\mathrm{PCa}$, is an urgent need. This would help developing novel and hopefully more effective therapeutic strategies with the ultimate aim to reduce morbidity and improve survival.

In addition, although considerable advancements have been made in recent years toward understanding metastatic PCa progression in bone, many questions still remain unsolved.

Methylglyoxal (MG) is a highly reactive by-product of glycolysis and a major precursor of advanced glycation end products (AGEs), especially 5-hydro-5-methylimidazolone (MGH1) [13]. Prior evidence suggests that MG adducts, including MG-H1 [14], may signal through receptors for AGEs (RAGE) [15]. In general, engagement of RAGE by AGEs can activate transcription factor NF-kB, which increases reactive oxidative species (ROS) formation $[14,16]$. However, it has been recently demonstrated that the binding of AGEs with RAGE can also directly trigger ROS intracellular accumulation that in turn actives NF-kB pathway [17]. Of note, RAGE is expressed by OB [14,18], where it plays a pivotal role in bone metabolism [19].

In cells, MG is primarily metabolized by the glutathione-dependent enzyme glyoxalase 1 (Glo1). Hence, by modulating MG, Glo1 prevents intracellular accumulation of MG-H1 from participating as an upstream factor to MG-derived AGEs-mediated cell responses.

The role of the Glo1/MG-AGEs axis in PCa progression is today well defined [13]. Glo1 is overexpressed in advanced metastatic PCa, where, through specific MG-derived AGEs, it participates in cancer survival [20,21], PTEN/PI3K/AKT/mTOR signaling- and epithelial-to-mesenchymal transition (EMT)-related metastatic behavior [22,23], in addition, contributes to maintaining an immunosuppressive microenvironment through MG-H1mediated PD-L1 up-regulation [24]. Whether Glo1/MG-H1 axis is also implicated in the mechanisms of PCa cells-driven bone metastases has never been investigated before.

Hence, recognized that bone metastases occurrence requires a constant dialogue between and reciprocal changes of both PCa and bone resident stromal cells, particularly OB [6], given that MG-AGEs, including MG-H1, can be secreted by cells [14] and act as paracrine signaling molecules through RAGE [15] to control bone metabolism [19], in the present study we investigated whether, and through which mechanism, MG-H1 might represent a novel agent implicated in the cross-talk between PCa and bone cells to possibly drive PCa osteotropic metastasis. Indeed, we found that metastatic PCa cells secrete MG-H1 that binds to RAGE on human primary OB to reprogram their phenotype into a less-differentiate one, endowed with some PCa-specific molecular features, in a mechanism involving ROS formation and NF-kB pathway activation. 


\section{Results}

2.1. Conditioned Medium (CM) from PC3 Bone Metastasis-Derived PCa Cells Contains MG-Originated MG-H1

To investigate whether PC 3 bone metastasis-derived PCa cells affected the homeostasis of human OB through MG-H1 secretion, PC3 were firstly cultured for 6 and $24 \mathrm{~h}$ in a humidified atmosphere at $37^{\circ} \mathrm{C}$, and the culture medium (conditioned medium, CM) was used to determine the levels of MG-H1 by a specific ELISA assay and Western blot (WB). As a control, the levels of MG-H1 were evaluated in the specific growth medium of OB, where they were cultured for the same period of time (control, CTR). Finally, the levels of MG-H1 were also determined in the fresh growth medium of both OB and PC 3 cells before it was administrated to cells. As shown in Figure 1, MG-H1 was present only in PC3 CM, while nor CTR cells (Figure 1) nor OB and PC 3 cells fresh medium (Figure S1) contained it. To prove that MG-H1 release was specifically associated with bone metastasis-derived PC3 cells, LNCaP cells, derived from a left supraclavicular lymph node metastasis and DU-145 cells, derived from a central nervous system metastasis, were grown for $24 \mathrm{~h}$ in RPMI medium [22] and MG-H1 was evaluated by WB in their CM. Finally, to show that MG-H1 was specifically released by PCa cells, also the non-cancerous PNT2 cells were cultured for $24 \mathrm{~h}$ in RPMI medium, and MG-H1 was measured in CM as above. As shown in Figure S1, none of these cells produced and secreted MG-H1, suggesting that MG-H1 release was specific to PCa cells disseminating to the bone.

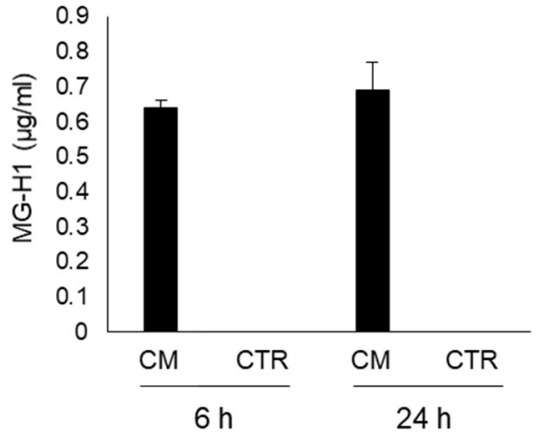

(a)

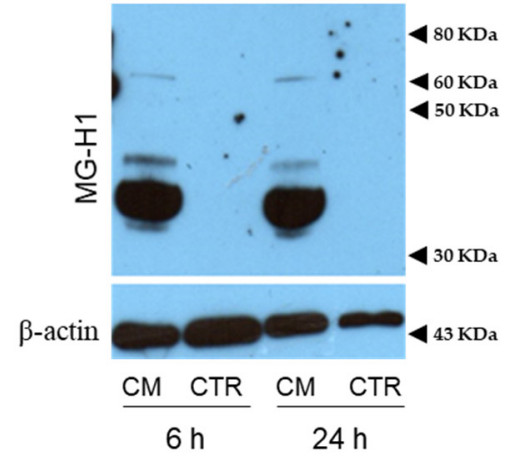

(b)

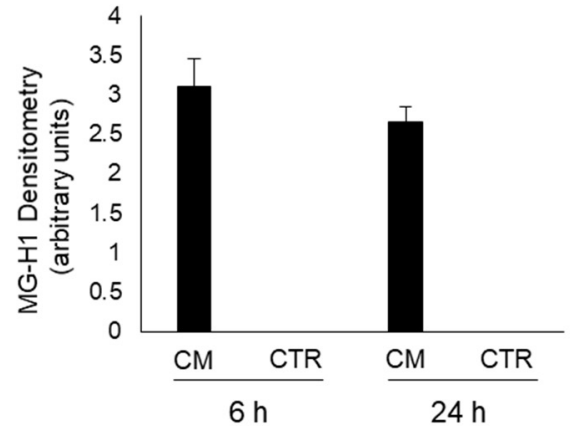

Figure 1. Level of methylglyoxal (MG)-derived 5-hydro-5-methylimidazolone (MG-H1) in the conditioned medium (CM) from PC3 bone metastasis-derived prostate cancer (PCa) cells. MG-H1 levels were measured by (a) a specific ELISA kit and (b) Western blot. In particular, PC 3 were cultured for 6 and $24 \mathrm{~h}$ in a humidified atmosphere at $37^{\circ} \mathrm{C}$, and the culture medium they grew in (CM) was used to determine the levels of MG-H1. As a control (CTR), the levels of MG-H1 were also evaluated in the $\mathrm{CM}$, where $\mathrm{OB}$ was cultured for the same period of time. $\beta$-actin was used as internal control, in agreement with Kwon et al. [25]. The histograms indicate the mean \pm SD of three different cultures, and each was tested in duplicate.

\subsection{Effect of $C M$ from $P C 3$ Cells on Human $O B$ Viability and Morphology}

We then treated human primary OB with PC 3 cells CM, containing MG-H1, or with OB growth medium (CTR) for 6 and $24 \mathrm{~h}$ and investigated OB viability and morphology. As shown in Figure 2a, PC3 CM did not influence OB viability at both exposure times compared with CTR cells, suggesting that it was not toxic to OB. Conversely, it was able to modify OB morphology, evaluated by phase-contrast microscopy, at $24 \mathrm{~h}$ postexposure (Figure $2 b$ ). In particular, $\mathrm{OB}$ exposed to $\mathrm{CM}$ assumed an elongated spindleshaped morphology, very similar to that of mesenchymal cells, compared with the typical cobblestone, cuboidal one of the mature OB in CTR cells. Interestingly, PC3 CM exposure induced in $\mathrm{OB}$ also the formation of thin but well-developed filopodia-like protrusions (Figure 2b, arrows). Altogether, these results suggested that PC3 cells boosted OB into a mesenchymal-like phenotype and that, since $\mathrm{OB}$ originate from bone marrow mesenchymal cells, characterized by a spindle-shaped morphology and typically exhibiting multiple, 
thin protrusions [26], that $\mathrm{PC} 3$ cells were able to activate in $\mathrm{OB}$ a dedifferentiation program, very likely through MG-H1 secretion in a paracrine way.

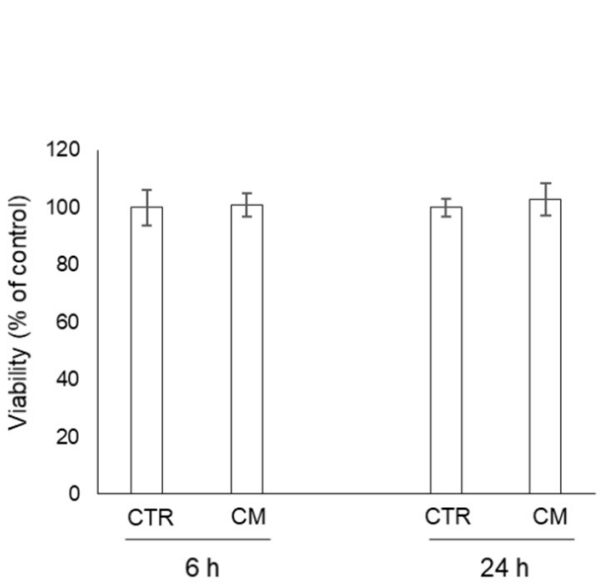

(a)
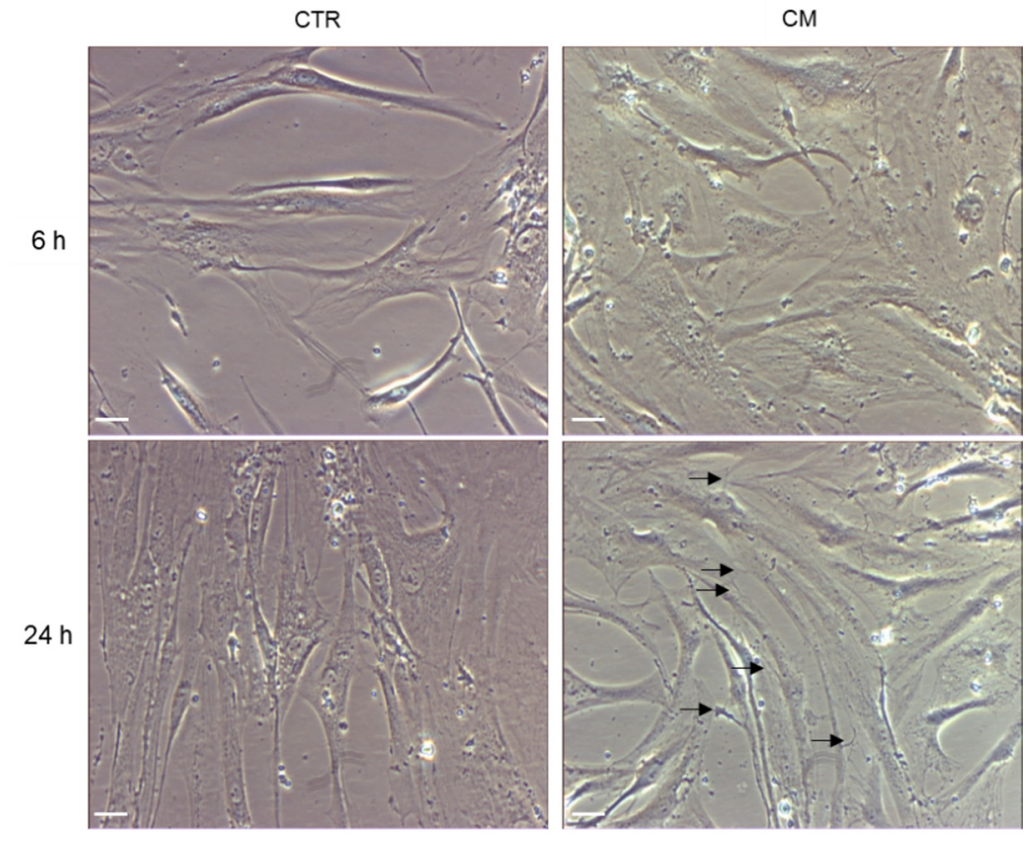

(b)

Figure 2. Effect of conditioned medium (CM) from PC3 bone metastasis-derived prostate cancer (PCa) cells on human primary osteoblasts (OB) viability and morphology. (a) cell viability measured by MTT assay and (b) cell morphology by means of light microscopy were evaluated in OB exposed for 6 and $24 \mathrm{~h}$ to CM from PC 3 cells. Control cells (CTR) are represented by $\mathrm{OB}$ cultured for the same period of time in their specific growth medium. The histogram indicates the mean \pm SD of three different cultures, and each was tested in duplicate. Scale bar $=30 \mu \mathrm{m}$. Arrows indicate filopodium-like protrusions.

\subsection{CM from PC3 Cells Alters in OB the mRNA Expression of Specific Markers Associated with Mesenchymal Trans-Differentiation}

To further prove that PC3 cells could induce the cellular regression of the mature phenotype of human $\mathrm{OB}$ to a less-differentiated, mesenchymal cell-like one, through the secretion of MG-H1, we evaluated, at the transcript level, the expression profile of markers typically associated with the mesenchymal trans-differentiation process, namely vimentin (VIM) [27], alpha-smooth muscle actin ( $\alpha$-SMA) [28], and transforming growth factor beta (TGF- $\beta 1$ ), a pivotal factor in OB trans-differentiation [29]. In parallel, the transcript level of some OB-specific adhesion proteins, namely cadherin 11 (CDH11) [30], integrin $\beta 1$ (ITGB1) [31], and integrin $\alpha 3$ (ITGA3) [32], were evaluated. In line with the morphological results, we found that $\mathrm{CM}$ from $\mathrm{PC} 3$ cells induced in $\mathrm{OB}$ a significant increase in VIM and $\alpha$-SMA mesenchymal cells markers as well as of TGF- $\beta 1$ (Figure 3a), while it decreased CDH11, ITGB1, and ITGA3 adhesion molecules (Figure 3b), compared with CTR cells. Hence, these data also confirmed at the molecular level the observed morphological changes, thus further supporting the hypothesis that $\mathrm{PC} 3$ cells were able to reprogram mature OB into a less-differentiated mesenchymal-like stage through MGH1 release. Moreover, these findings suggested that the diminished levels of ITGB1 and ITGA3 expression possibly reflected an inefficient cell adhesion, typically associated with a mesenchymal phenotype. 

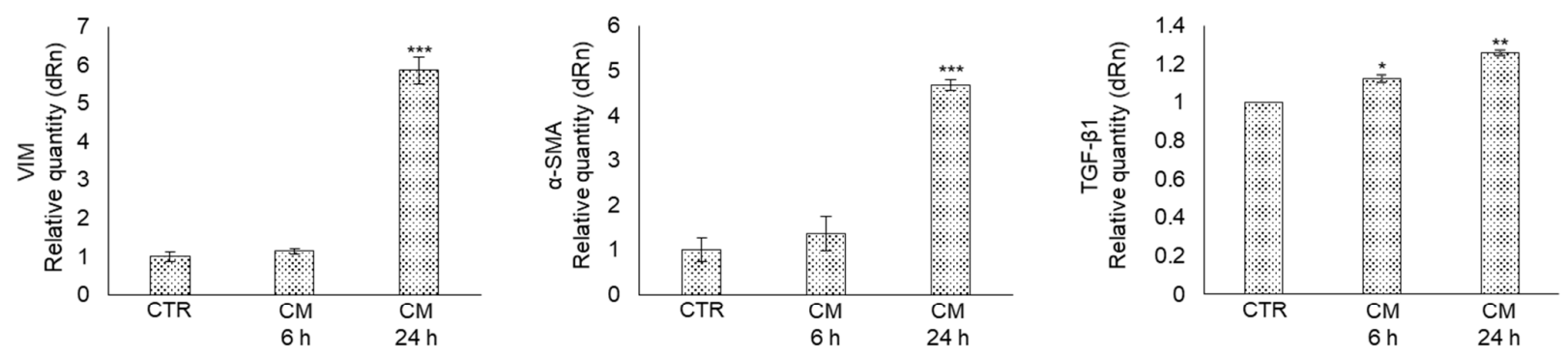

(a)
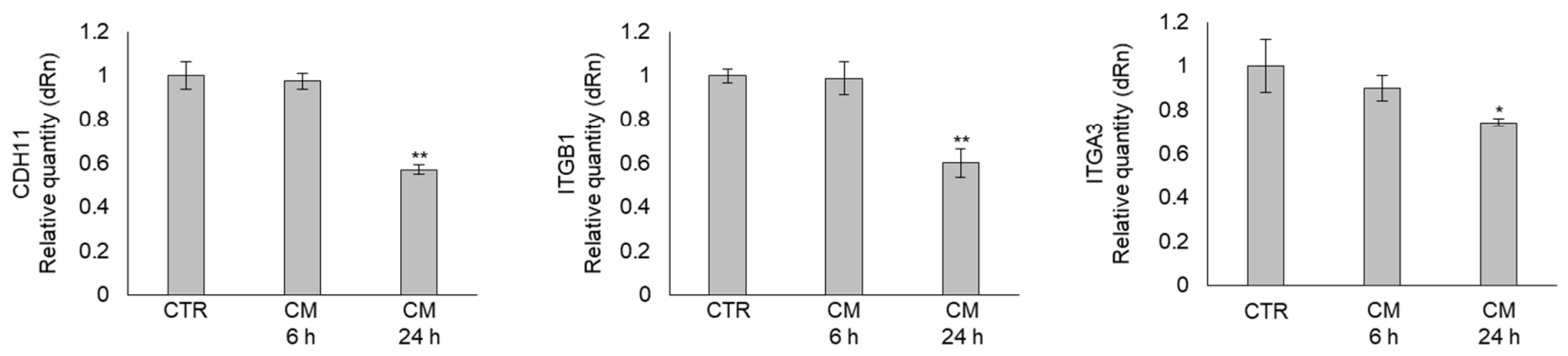

(b)

Figure 3. Effect of conditioned medium (CM) from PC3 bone metastasis-derived prostate cancer (PCa) cells on the mRNA expression of mesenchymal trans-differentiation-associated markers in human primary osteoblasts (OB). Transcript levels of (a) vimentin (VIM), alpha-smooth muscle actin ( $\alpha$-SMA) and transforming growth factor- $\beta 1$ (TGF- $\beta 1$ ) mesenchymal markers or (b), cadherin 11 (CDH11), integrin $\beta 1$ (ITGB1) and integrin alpha 3 (ITGA3) adhesion molecules were evaluated by real-time PCR in OB exposed for 6 and $24 \mathrm{~h}$ to CM from PC 3 cells. Control cells (CTR) are represented by OB cultured for the same period of time in their specific growth medium. Two experimental CTRs were performed for each exposure time; being both of them set at 1 , each histogram reports only one CTR. The histogram indicates the mean \pm SD of two different cultures, and each was tested in triplicate; ${ }^{*} p<0.05,{ }^{* *} p<0.01,{ }^{* * *} p<0.001$ versus CTR.

\subsection{CM from PC3 Cells Alters the mRNA Expression of Specific Markers Associated with OB Mature Phenotype}

To further prove that PC3 cells were able to induce a shift of the mature phenotype of human $\mathrm{OB}$ to a less-differentiated one, we also determined the transcript level of some important molecules characteristic of OB mature phenotype, typically involved in osteogenic differentiation, namely runt-related transcription factor 2 (Runx2), collagen type I $\alpha 1$ (Col1 $\alpha 1)$, osteonectin (ON), osterix (OSX) [33] and the pre-osteoblast state marker, cluster of differentiation protein 44 (CD44) [34]. As shown in Figure 4, the mRNA expression of all OB-specific markers significantly decreased upon PC 3 CM exposure at $24 \mathrm{~h}$. Conversely, PC3 CM induced a significant increase in CD44 transcript levels with respect to OB grown in their own medium. Overall, this evidence further supported the role of PC3 cells in reverting back OB to a less-differentiated phenotype through MG-H1 release.
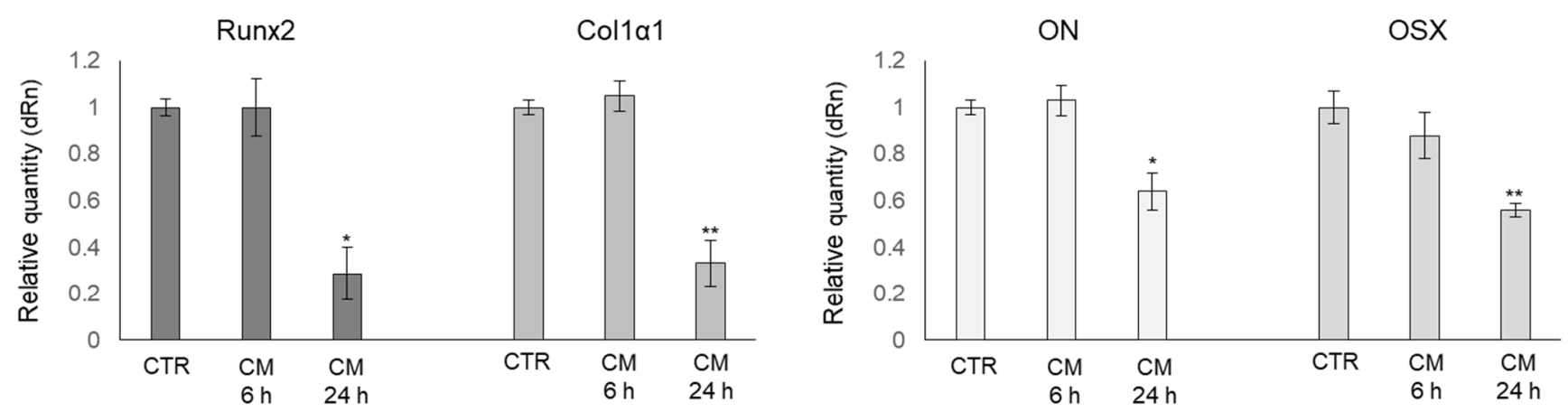

Figure 4. Cont. 


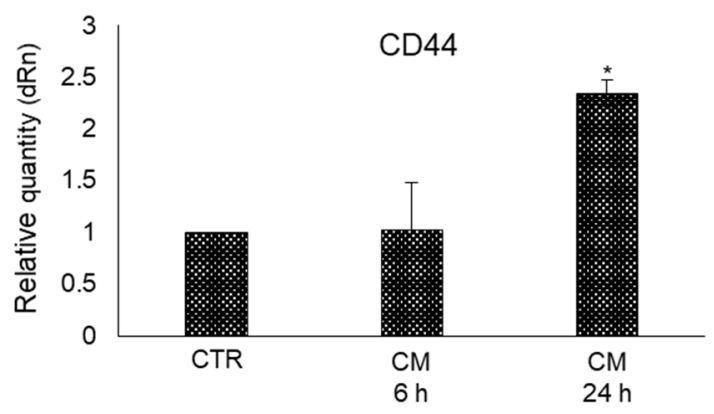

Figure 4. Effect of conditioned medium (CM) from PC3 bone metastasis-derived prostate cancer (PCa) cells on the mRNA expression of osteogenic differentiative markers runt-related transcription factor 2 (Runx2), collagen type I $\alpha 1$ (Col1 $\alpha 1$ ), osteonectin (ON), osterix (OSX), and the pre-osteoblast state marker, cluster of differentiation protein 44 (CD44) in human primary osteoblasts (OB). Transcript levels were evaluated by real-time PCR in OB exposed for 6 and $24 \mathrm{~h}$ to CM from PC3 cells. Control cells (CTR) are represented by OB cultured for the same period of time in their specific growth medium. Two experimental CTRs were performed for each exposure time; being both of them set at 1, each histogram reports only one CTR. The histogram indicates the mean \pm SD of two different cultures, and each was tested in triplicate. ${ }^{*} p<0.05$, ${ }^{* *} p<0.01$ versus CTR.

2.5. The Trans-Differentiation of OB Phenotype to A Mesenchymal-like One upon PC3 Cells CM Exposure Is Accompanied by Increased Migration/Invasion but Not Proliferation

As known, mesenchymal or mesenchymal-like cells are typically characterized by increased proliferation and motility [35]. Hence, we explored whether the trans-differentiation of OB phenotype to a mesenchymal-like one upon PC3 cells CM exposure was accompanied by increased migration/invasion and/or proliferation activities. As shown in Figure 5, OB exposed to PC3 cells CM for $24 \mathrm{~h}$ became more motile and invasive, while they did not change cell proliferation, thus further showing PC3 cells induced OB dedifferentiation also at the functional level, at least as far as migration and invasion are concerned, as expected for cells acquiring mesenchymal-like morphological traits.

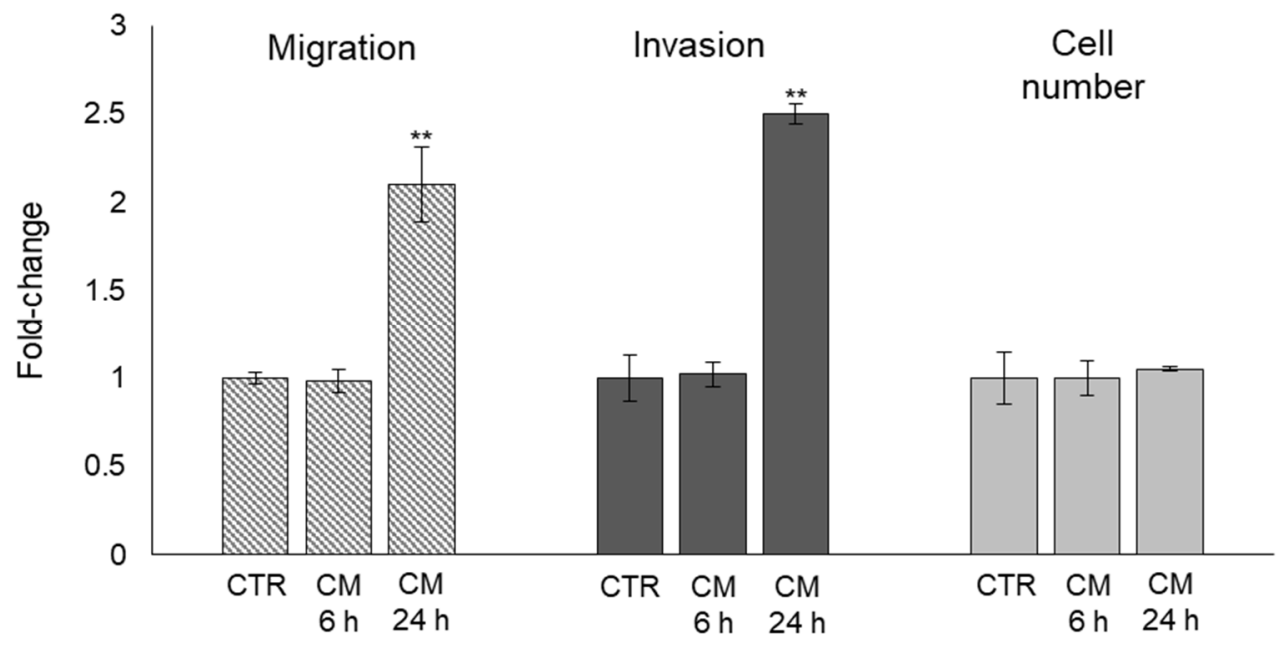

Figure 5. Effect of conditioned medium (CM) from PC3 bone metastasis-derived prostate cancer (PCa) cells on human primary osteoblasts $(\mathrm{OB})$ migration, invasion, and proliferation. Migration and invasion were evaluated by specific assays, while cell proliferation by cell counting, in OB exposed for 6 and $24 \mathrm{~h}$ to CM from PC3 cells. Control cells (CTR) are represented by OB cultured for the same period of time in their specific growth medium. Two experimental CTRs were performed for each exposure time; being both of them set at 1 , each histogram reports only one CTR. The histogram indicates the mean $\pm \mathrm{SD}$ of two different cultures, and each was tested in triplicate. ${ }^{* *} p<0.01$, versus CTR. 


\section{6. $C M$ from $P C 3$ Cells Alters in $O B$ the $m R N A$ Expression of Proteins Involved in the Formation of Dynamic Cell Protrusions}

To further support the cytoplasmic rearrangement processes observed by the morphological analysis and presumably associated with the observed increased OB motility, we then evaluated the mRNA levels of some key proteins involved in the cytoskeletal dynamic formation of cell protrusion (e.g., filipodia) [36]. In particular, we considered fascin (FASC), profilin 1 (PFN1), cofilin (COFN), and radixin (RADX) [32]. As shown in Figure 6, OB treated with PC3 CM presented a marked up-regulation of all the considered genes compared with control cells, also sustaining at the molecular level the occurrence of cytoplasmic rearrangement processes and, in particular, the formation of filopodia-like protrusions already evidenced by the morphological analysis.
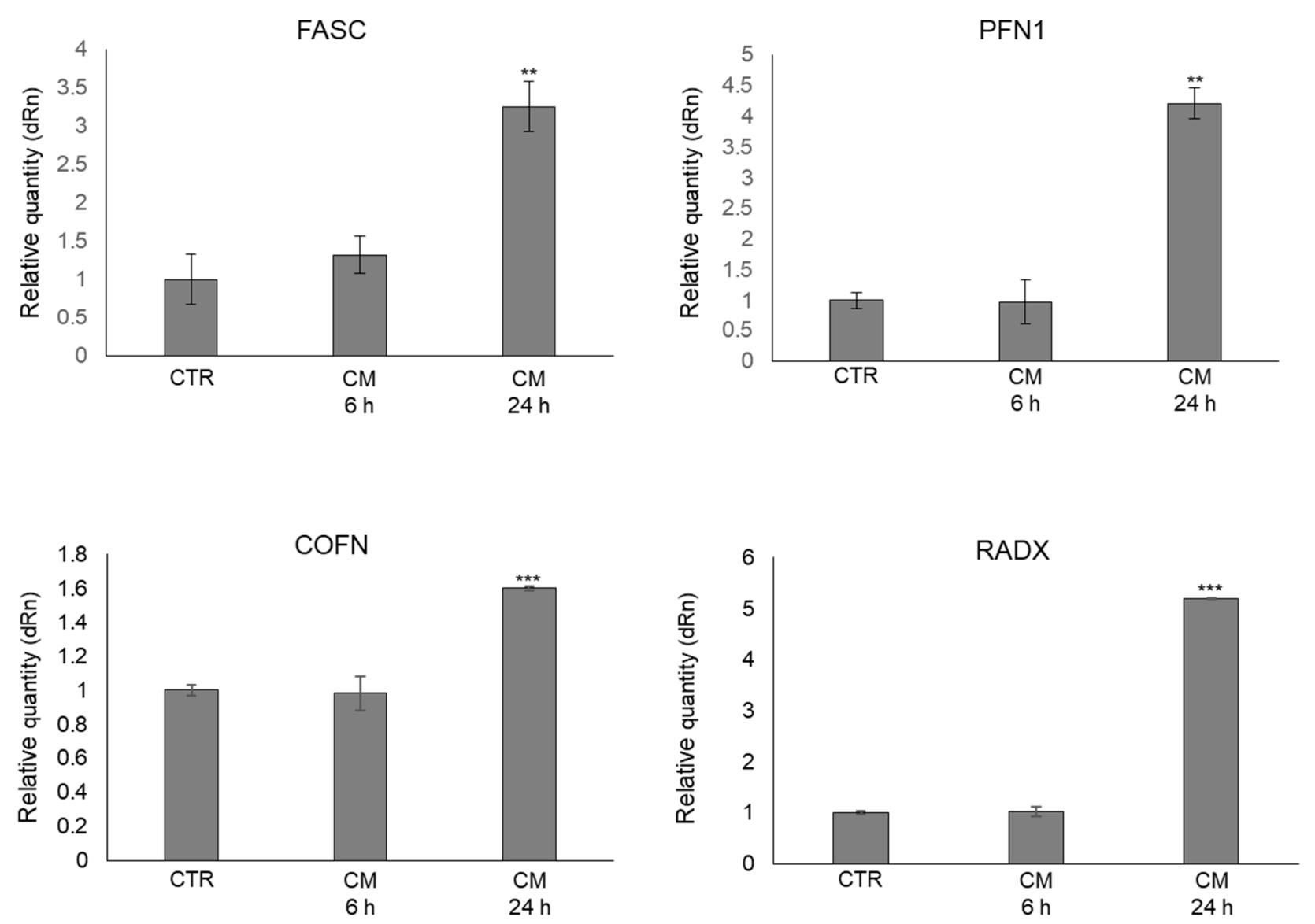

Figure 6. Effect of conditioned medium (CM) from PC3 bone metastasis-derived prostate cancer (PCa) cells on the mRNA expression of some key proteins involved in the cytoskeletal dynamic formation of cell protrusion in human primary osteoblasts (OB). Transcript levels were evaluated by real-time PCR in OB exposed for 6 and $24 \mathrm{~h}$ to CM from PC 3 cells. Control cells (CTR) are represented by OB cultured for the same period of time in their specific growth medium. Two experimental CTRs were performed for each exposure time; being both of them set at 1, each histogram reports only one CTR. The histogram indicates the mean \pm SD of two different cultures, and each was tested in triplicate. FASC, fascin; PFN1, profilin 1; COFN, cofilin; RADX, radixin. ${ }^{* *} p<0.01,{ }^{* * *} p<0.001$, versus CTR.

\subsection{CM from PC3 Cells Affects OB Mineralization Activity}

PCa bone metastases are characterized by abnormally hypermineralized bone due to OB hyperactivity [6]. To investigate whether MG-H1-containing PC3 cells CM could somehow take part in this anomalous process, we first measured the mRNA expression of proteins typically involved in $\mathrm{OB}$ extracellular matrix mineralization, namely the noncollagenous protein osteocalcin (OC) and osteopontin (OP) [37]. In comparison with 
the control cells, the mRNA expression of OC and OP were significantly increased in $\mathrm{OB}$ exposed to PCa cells $\mathrm{CM}$ at $24 \mathrm{~h}$ post-exposure (Figure 7a). Subsequently, since OB mineralization also requires the deposition of the inorganic component (mineralized matrix) made up of hydroxyapatite crystals rich in calcium and phosphate [38], we evaluated the effect of CM from PC 3 cells on OB mineral formation, evaluating calcium deposits by alizarin red staining method. As displayed in Figure 7b, PC3 cells-derived CM enhanced mineralization of $\mathrm{OB}$ at $24 \mathrm{~h}$ compared with controls.

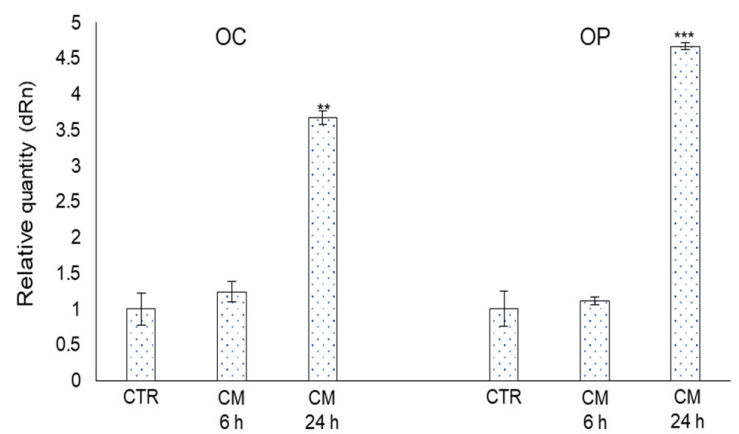

(a)

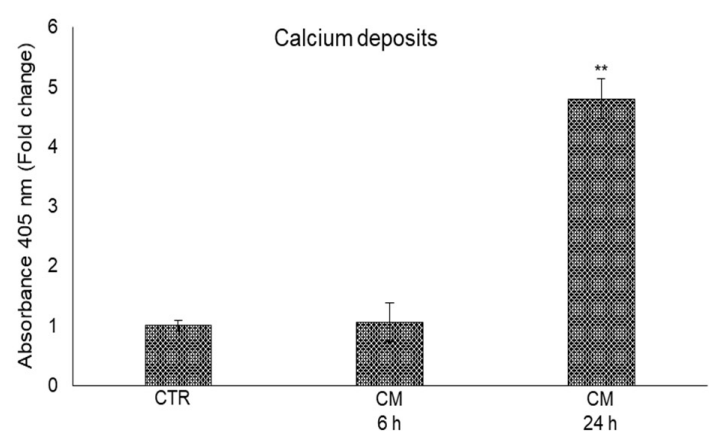

(b)

Figure 7. Effect of conditioned medium (CM) from PC3 bone metastasis-derived prostate cancer (PCa) cells on the mRNA expression of some key proteins typically involved in $\mathrm{OB}$ extracellular matrix mineralization, namely the non-collagenous protein osteocalcin (OC) and osteopontin (OP) (a), and on the formation of calcium deposits in human primary osteoblasts (OB) (b). Transcript levels were evaluated by real-time PCR while calcium deposits were measured by the alizarin red staining method in OB exposed for 6 and $24 \mathrm{~h}$ to CM from PC3 cells. Control cells (CTR) are represented by OB cultured for the same period of time in their specific growth medium. Two experimental CTRs were performed for each exposure time; being both of them set at 1 , each histogram reports only one CTR. The histogram indicates the mean \pm SD of two different cultures, and each was tested in triplicate. ${ }^{* *} p<0.01,{ }^{* * *} p<0.001$.

\subsection{CM from PC3 Cells Induces De Novo Expression of the Prostate-Specific Antigens PSA and $P S M A$ in $O B$}

Patients with metastatic PCa usually present high serum prostate-specific antigen (PSA) levels, and it has been suggested that PSA may participate in PCa osteoblastic metastases $[39,40]$. Hence, we investigated whether CM from PC3 cells containing MG$\mathrm{H} 1$ was able to induce PSA and, possibly, membrane PSA (PSMA) expression, in OB. Surprisingly, we found that the mRNA expression of both prostate-specific markers was induced de novo in OB exposed to PC3 CM compared with control cells (Figure 8).
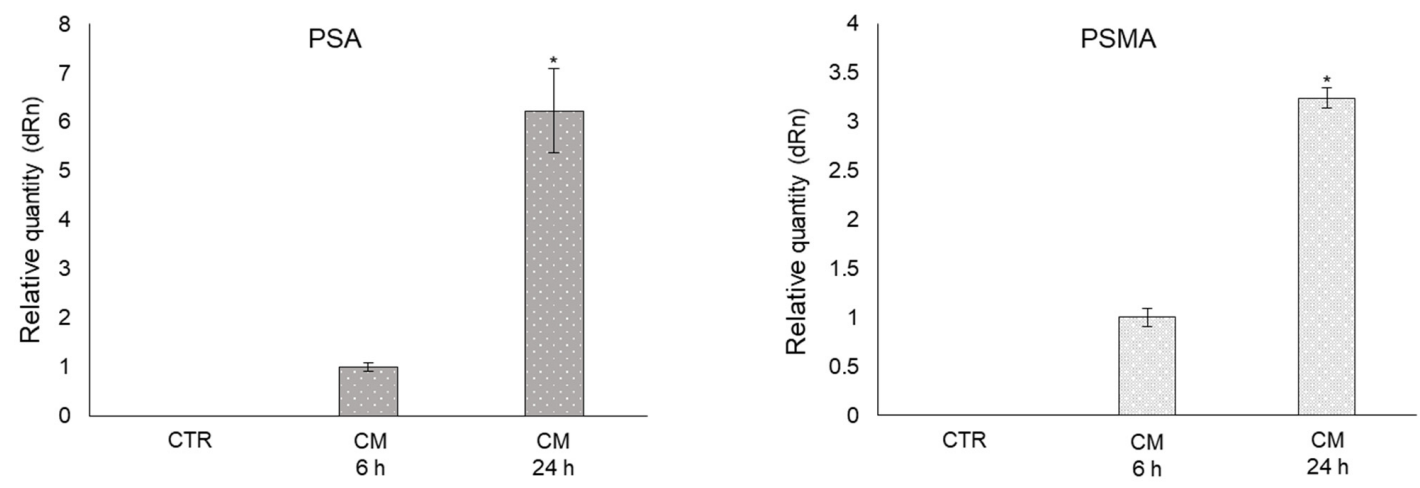

Figure 8. Conditioned medium (CM) from PC3 cells induces de novo expression of the prostate-specific antigens PSA and PSMA (prostate-specific membrane antigen) in OB. Transcript levels were evaluated by real-time PCR in OB exposed for 6 and $24 \mathrm{~h}$ to CM from PC3 cells. Control cells (CTR) are represented by OB cultured for the same period of time in their specific growth medium. Two experimental CTRs were performed for each exposure time; being both of them set at 1 , each histogram reports only one CTR. The histogram indicates the mean $\pm \mathrm{SD}$ of two different cultures, and each was tested in triplicate. ${ }^{*} p<0.05$. 
2.9. MG-derived MG-H1 Is a Novel Paracrine Factor Released by Bone Metastasis-Derived PC3 Cells to Reprogram Human OB into a Dedifferentiated, Mesenchymal-, and Malignant-Like Phenotype

Overall, our results suggested that MG-H1, released from PC3 cancer cells, was able to induce $\mathrm{OB}$ phenotype regression consisting in the assumption of mesenchymal-like and prostate-specific traits and in gaining an enhanced mineralization capability, all these being hallmarks of PCa-associated bone metastases. To prove all this causatively, we pre-treated PC3 cells with aminoguanidine (AG), a specific MG scavenger [23], thus able to prevent MGderived MG-H1 formation and release into the medium (Figure S2), for $6 \mathrm{~h}$ at $1 \mathrm{mM}$. Then, we collected the CM derived from PC 3 treated with AG and administrated it to OB. Finally, OB morphology (Figure 9a), the expression of mesenchymal trans-differentiation-associated markers (VIM, $\alpha$-SMA, TGF- $\beta 1$, CDH11, ITGB1, ITGA3) (Figure 9b), the expression of markers associated with OB mature phenotype (Runx2, Col1 $\alpha 1, \mathrm{ON}, \mathrm{OSX}$ ), the expression of the pre-osteoblast state marker CD44 (Figure 9c), migration and invasion (Figure 9d), the mRNA expression of proteins involved in the formation of filopodia-like protrusions (FASC, PFN1, COFN, RADX) (Figure 9e), bone mineralization through OC and OP expression and calcium deposits formation (Figure 10a), and the expression of the prostate-specific markers PSA/PSMA (Figure 10b), were evaluated compared with OB treated with PC3 cells CM not pre-treated with AG. As shown in Figures 9 and 10, AG pre-treatment was able to completely abrogate the effects induced by MG-H1-containing CM on the above molecules and processes, thus confirming that MG-derived MG-H1 is a novel paracrine factor released by bone metastasis-derived PC 3 cells to reprogram human OB into a mesenchymal-, malignant-like, and more invasive phenotype. These results were additionally confirmed by inducing MG-H1 accumulation through Glo1 silencing since this maneuver potentiated the studied responses (Figure S3).

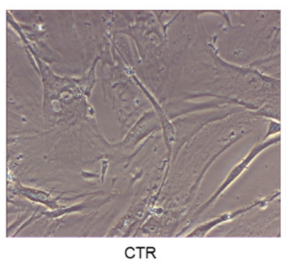

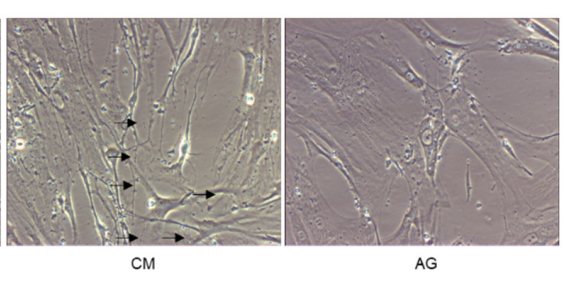

(a)

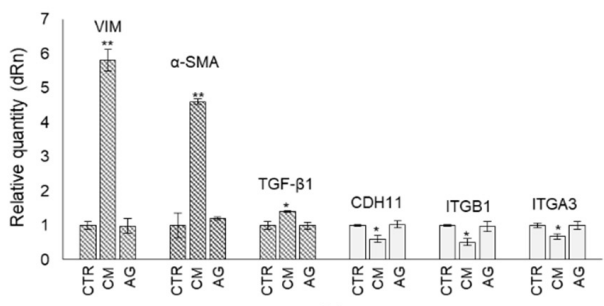

(b)

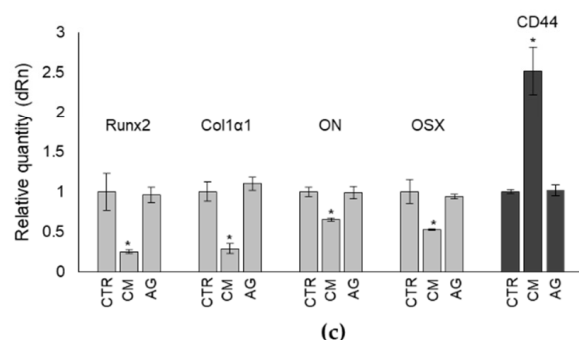

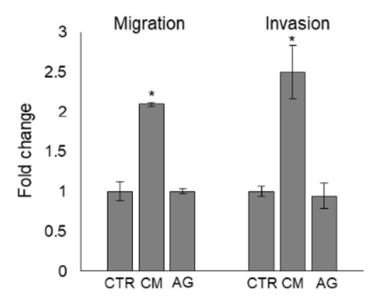

(d)

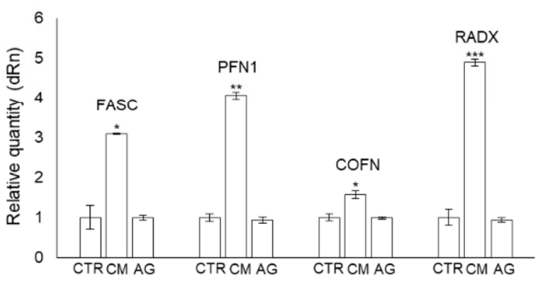

(e)

Figure 9. Methylglyoxal (MG)-derived 5-hydro-5-methylimidazolone (MG-H1) is a novel paracrine factor released by bone metastasis-derived PC3 cells to reprogram human osteoblasts (OB) into a mesenchymal-, malignant-like phenotype. (a) cell morphology by means of light microscopy, the expression of (b) mesenchymal trans-differentiation-associated markers (VIM, $\alpha$-SMA, TGF- $\beta 1$, CDH11, ITGB1, ITGA3), (c) markers associated with OB mature phenotype (Runx2, Col1 $\alpha 1$, ON, OSX) and the pre-osteoblast state marker CD44 (c) and (e) proteins involved in the formation of filopodia-like protrusions (FASC, PFN1, COFN, RADX) as well as (d) migration and invasion were evaluated in OB exposed for $24 \mathrm{~h}$ to CM from PC3 cells and to CM from PC3 pre-treated (6 h) with the specific MG scavenger aminoguanidine (AG) (1 mM). Control cells (CTR) represent $\mathrm{OB}$ cultured for the same period of time in their specific growth medium. Transcript levels were evaluated by real-time PCR. The histogram indicates the mean \pm SD of three different cultures, and each was tested in duplicate. Scale bar $=30 \mu \mathrm{m}$. Arrows indicate filopodium-like protrusions. VIM, vimentin; $\alpha$-SMA, alpha smooth muscle actin; CDH11, cadherin 11; ITGB1, integrin $\beta 1$; ITGA3, integrin $\alpha 3$; FASC, fascin; PFN1, profilin 1; COFN, cofilin; RADX, radixin. ${ }^{*} p<0.05$, ** $p<0.01, * * * 0.001$, versus CTR and AG. 

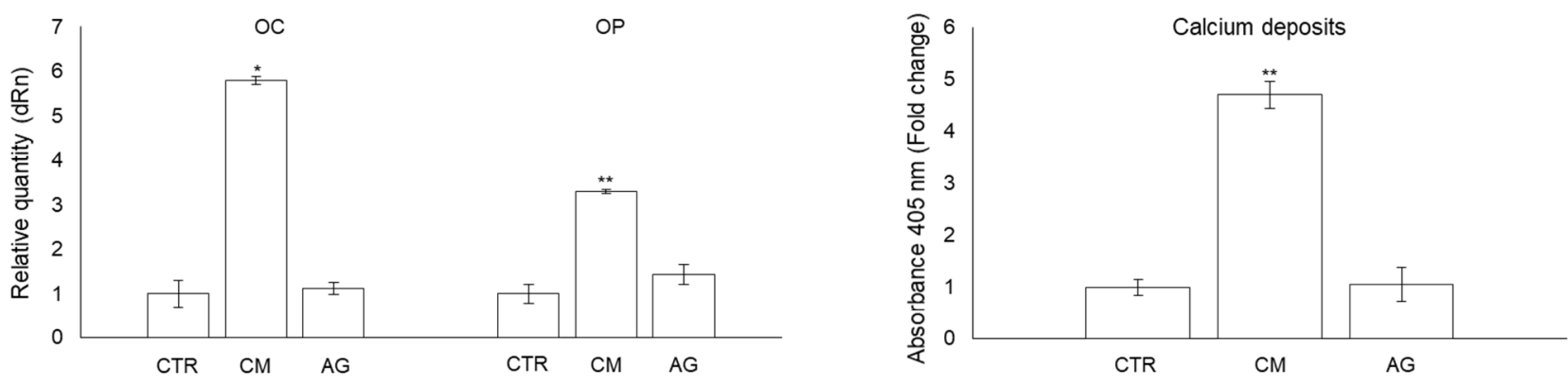

(a)

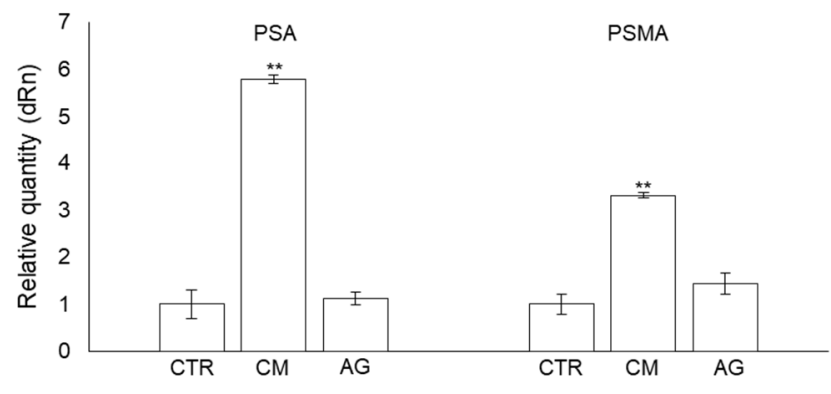

(b)

Figure 10. Methylglyoxal (MG)-derived 5-hydro-5-methylimidazolone (MG-H1) is a novel paracrine factor released by bone metastasis-derived PC3 cells to alter human osteoblasts $(\mathrm{OB})$ mineralization and induce a prostate-specific phenotype. (a) expression of bone mineralization-participating proteins osteocalcin (OC) and osteopontin (OP) and calcium deposits formation, (b) mRNA expression of prostate-specific antigen (PSA) and prostate-specific membrane antigen (PSMA) evaluated in OB exposed for $24 \mathrm{~h}$ to conditioned medium (CM) from PC3 cells and to CM from PC 3 pre-treated (6 h) with the specific MG scavenger aminoguanidine (AG) $(1 \mathrm{mM})$. Control cells (CTR) represent OB cultured for the same period of time in their specific growth medium. Transcript levels were evaluated by real-time PCR while calcium deposits were measured by the alizarin red staining method. The histogram indicates the mean \pm SD of three different cultures, and each was tested in duplicate. ${ }^{*} p<0.05,{ }^{* *} p<0.01$, versus CTR and AG.

2.10. MG-Derived MG-H1 Released by Bone Metastasis-Derived PC3 Cells Reprograms Human $O B$ into a Mesenchymal-, Malignant-like Phenotype through a RAGE-Dependent Mechanism with the Involvement of ROS and NF-kB Signaling

MG-H1 can signal through receptor for AGEs (RAGE) [15] to trigger ROS intracellular accumulation that, in turn, actives NF-kB pathway [17]. Hence, we investigated whether MG-H1-induced OB dedifferentiation occurred through a RAGE-dependent mechanism, possibly involving reactive oxidative species (ROS) and the NF-kB pathway. Indeed, we found that PC3 CM-containing MG-H1 induced a significant increase in RAGE expression at both transcriptional and protein levels (Figure 11a), ROS intracellular amount (Figure 11b), and NF-kB-p65 nuclear levels (Figure 11c), compared with OB controls, while CM from PC3 pre-treated with AG prevented all these changes (Figure 11a,b), bringing NF-kB-p65 levels even under those of control (Figure 11c). These results suggested that MG-derived MG-H1 released by bone metastasis-derived PC3 cells reprograms human OB into a mesenchymal-, malignant-like phenotype through a RAGE-dependent mechanism. Importantly, upon MGH1-containing PC3 CM exposure, blockade of RAGE with the high-affinity RAGE-specific inhibitor FPS-ZM1 [41,42], rescued OB dedifferentiation and re-wiring, evaluated by VIM, CADH11, Runx 2, CD44, migration, and PSMA levels (Figure 11d). 


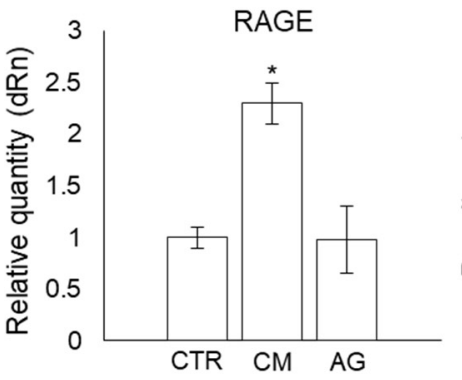

(a)

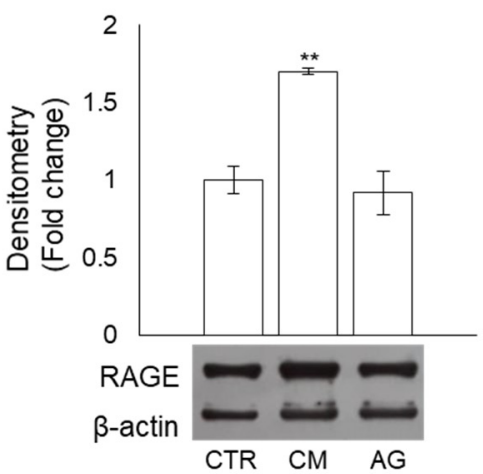

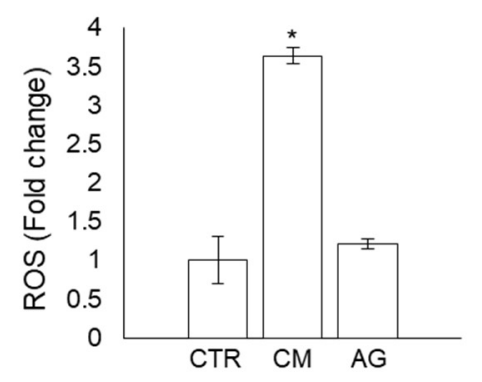

(b)

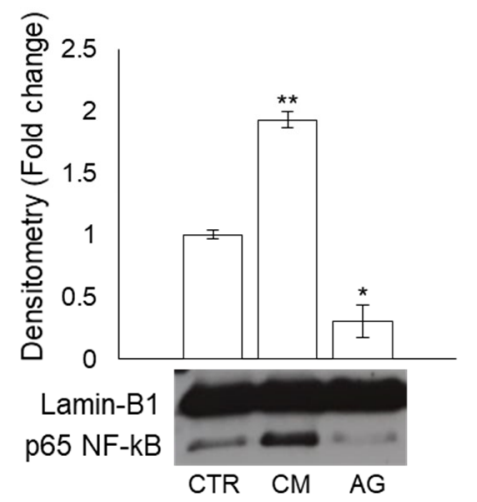

(c)

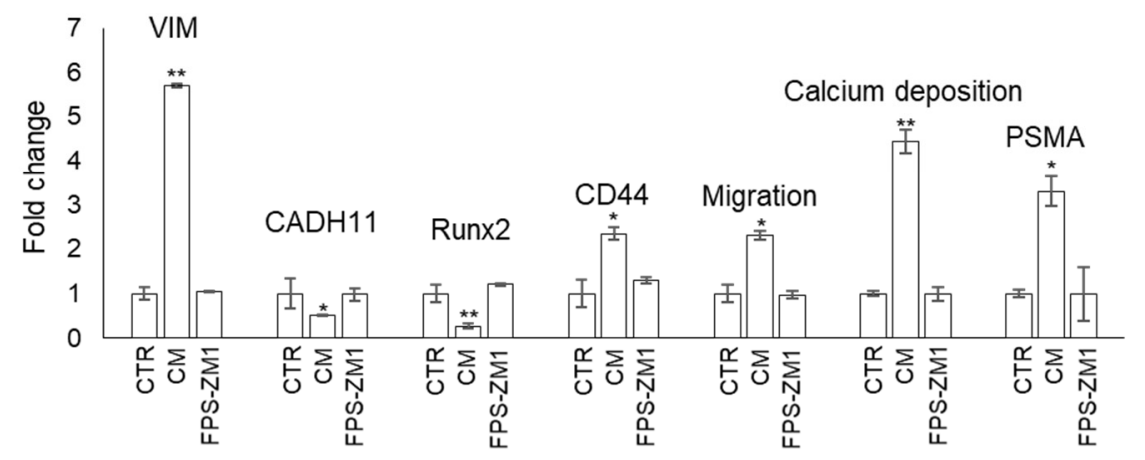

(d)

Figure 11. Methylglyoxal (MG)-derived 5-hydro-5-methylimidazolone (MG-H1) released by bone metastasis-derived PC3 cells reprograms human osteoblasts $(\mathrm{OB})$ into a mesenchymal- malignant-like phenotype through a receptor for advanced glycation end products (RAGE)-dependent mechanism with the involvement of reactive oxidative species (ROS) and NF-kB signaling. (a) expression of RAGE, measured by real-time PCR and western blot; (b) intracellular levels of ROS, evaluated by $2^{\prime}, 7^{\prime}$-dichlorodihydrofluorescein diacetate; (c) p 65 NF-kB nuclear expression by western blot and (d) trans-differentiation, migration, and mineralization-related responses in not exposed OB (CTR) or OB exposed for $24 \mathrm{~h}$ to conditioned medium (CM) from PC3 cells or to CM from PC3 pre-treated (6 h) with the specific MG scavenger aminoguanidine (AG) (1 mM) or to PC3 CM in the presence of the RAGE antagonist FPS-ZM1. Control cells (CTR) represent OB cultured for the same period of time in their specific growth medium. The histogram indicates the mean $\pm \mathrm{SD}$ of three different cultures, and each was tested in duplicate. ${ }^{*} p<0.05,{ }^{* *} p<0.01$ versus CTR. VIM, vimentin; CADH11, cadherin 11; Runx2, runt-related transcription factor 2; CD44, cluster of differentiation protein 44; PSMA, prostate-specific membrane antigen.

Overall, these findings indicated that MG-derived MG-H1 released by bone metastasisderived PC3 cells reprogrammed human primary OB into a mesenchymal-, malignant-like phenotype through a RAGE-dependent mechanism with the involvement of ROS and NF-kB signaling.

\subsection{CM from LNCaP Cells, Devoid of MG-H1, Does Not Reprogram OB into a Dedifferentiated Malignant-like Phenotype}

The pivotal role played by MG-H1 in reprogramming OB into a dedifferentiated malignant-like phenotype was further confirmed by administrating $\mathrm{CM}$ from one of the cell lines devoid of MG-H1 (Figure S1), in particular LNCaP, on OB for $24 \mathrm{~h}$. As shown in Figure S4, CM from LNCaP did not affect OB proliferation, morphology, expression of vimentin and $\mathrm{CDH}$ (specific markers associated with mesenchymal transdifferentiation), Runx2 and CD44 (specific markers associated with OB mature phenotype), migration/invasion, OC expression and calcium deposits (for extracellular matrix mineralization) as well as PSA/PSMA expression. 


\subsection{Circulating Levels of MG-H1 in Bone Metastasis-Bearing Patients}

To provide a potential clinical value to our results, we finally measured the circulating levels of MG-H1 in patients with metastatic PCa $(n=30)$, previously enrolled [23]. In particular, among this cohort, we identified patients with bone metastases $(n=20)$ and patients with metastases to other organs $(n=10)$. In support of the mechanistic in vitro results, we found that patients with bone metastases presented significantly higher levels of MG-H1 than those with metastases to other organs (Figure 12).

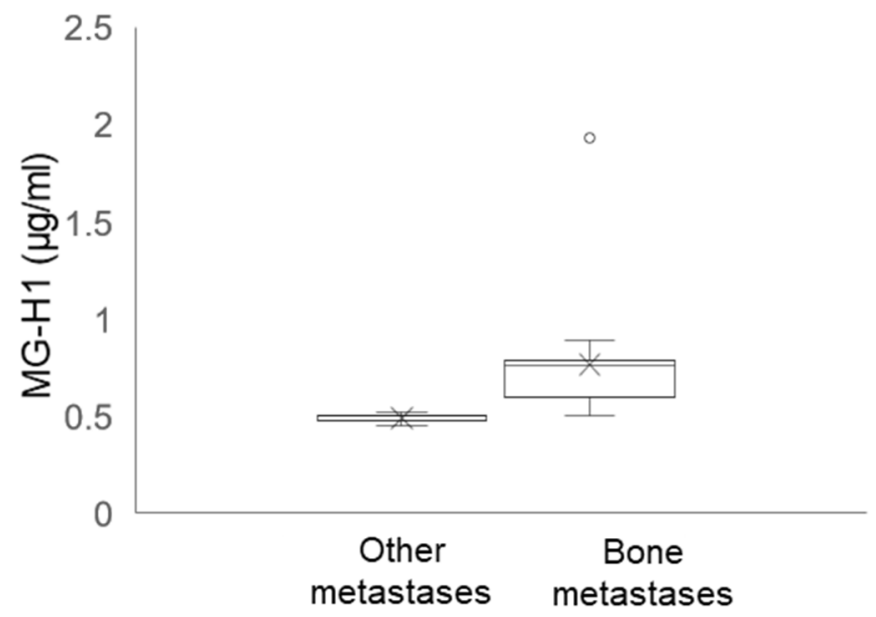

Figure 12. Circulating levels of 5-hydro-5-methylimidazolone (MG-H1) in bone metastasis-bearing patients divided into those with bone metastases $(n=20)$ and those with metastases from other organs (other metastases, $n=10$ ).

\section{Discussion}

Prostate cancer $(\mathrm{PCa})$ is the most common cancer in men in western countries, with a high incidence of bone metastases [43]. Due to osteoblasts (OB) hyperactivity, PCa bone metastases are typically characterized by an abnormal formation of the bone that is markedly more fragile and, consequently, more susceptible to fractures [6]. Colonization of PCa cells within the bone is complex and involves a network of interactions between cancer cells and $\mathrm{OB}$ [44] together with the production of paracrine signals and activation of signaling cascades modulated by numerous regulatory molecules. Hence, targeting the cross-talk between $\mathrm{PCa}$ and $\mathrm{OB}$ has become an attractive strategy to interfere with PCa bone metastasis. Indeed, several agents are currently in clinical trials to combat bone-metastatic PCa $[5,6]$. Unfortunately, therapies directed to PCa and/or OB-associated molecules have yielded disappointing clinical results [10-12], which suggests that our understanding of $\mathrm{PCa} / \mathrm{OB}$ dialogue in this neoplasia is still limited. In this study, we describe, for the first time, that MG-H1 is a novel paracrine factor specifically released from osteotropic $\mathrm{PCa}$ cells to reprogram human primary OB into a less-differentiate, mesenchymal-like phenotype, characterized by increased motility and expressing some prostate-specific traits, in a mechanism involving RAGE-driven ROS production and NF-kB pathway activation (Figure 13).

In particular, the observed dedifferentiation switch was evident by the fact that $\mathrm{OB}$ exposed to MG-H1-containing CM assumed a spindle-shape morphology, reduced osteogenic differentiation markers, decreased adhesive proteins, enhanced mesenchymal-like components and cell protrusions, acquiring motility properties. Moreover, MG-H1 increased $\mathrm{OB}$ mineralization activity, which is a characteristic of PCa osteoblastic metastases. Interestingly, MG-H1 induced in OB de novo expression of PSA and PSMA prostate-specific molecules. Although apparently surprising, this observation indeed is in agreement with the role of PSA as a crucial player in preparing bone microenvironment to favor PCa osteoblastic metastases, acting as a protease against some matrix proteins [39]. Similarly, it has been demonstrated that also PSMA can have peptidase and hydrolase activities and be 
involved in tissue regeneration and repair [45]. Hence, its participation in the remodeling of the bone-metastatic niche to favor bone metastasis formation is very plausible. Moreover, this membrane protein, highly expressed in aggressive metastatic PCa, can also have a proangiogenic function, which implies a possible role for PSMA in the bone-metastatic microenvironment also in this scenario. Hence, altogether our findings suggest that MG-H1 is a novel player in the dialogue between PCa cells and OB to promote bone metastases. In particular, MG-H1, through the receptor RAGE, would reverse OB mature phenotype and impair some of $\mathrm{OB}$ specialized functions (motility and mineralization) to boost them to create an ad hoc niche to accommodate bone disseminating PCa cells and favor their growth during cancer progression. Hence, our results are in agreement and add novel insight into the "seed and soil" hypothesis by Paget, according to which, to facilitate the formation of metastases, the "soil" (metastatic microenvironment, OB in our case) must be able to nourish "seeds" (disseminated PCa cells). Ultimately, changes in the bone "soil" by PCa cells through MG-H1 secretion, as here observed, can create a favorable growth environment for the metastasis of PCa. We also demonstrated that MG-H1 is able to remodel the bone-metastatic niche through a mechanism involving RAGE-dependent ROS production and NF-kB pathway activation. It is known that NF-kB can trigger ROS formation [14,16]. Similarly, emerging evidence shows that ROS can activate the NF-kB pathway [17] so that a strong interplay exists between these two actors, which, for this, are not mutually exclusive. Hence, we would like to point out that once MG-H1/RAGE complex is formed and drives ROS and NF-kB production/activation, it is also possible that a concomitant amplification of the downstream effects on OB dedifferentiation might occur due to ROS/NF-kB-positive feed-forward loop within a precise regulatory circuitry. Another important pathway in the regulation of bone-remodeling processes is $\mathrm{WNT} / \beta$ catenin signaling that has been shown to drive epithelial to mesenchymal transformation (EMT) of OB to induce their dedifferentiation [46]. Considering that here we observed a correlation between the assumption of mesenchymal traits with OB dedifferentiation and that oxidative stress, here induced by MG-H1, can activate the WNT pathway [47], the participation of this signaling pathway could also be very plausible, which deserves further investigation.

In the last decade, we have demonstrated that Glo1, by scavenging MG and, consequently by preventing MG-derived MG-H1 formation, plays a pivotal role in PCa progression through both apoptosis $[20,21]$ and EMT $[22,23]$ control. Very recently, we have also found that Glo1/MG-H1 axis contributes to maintaining an immunosuppressive microenvironment by modulating PD-L1 expression [24]. Here, we added further information to the oncogenic role of the Glo1/MG-H1 pathway in PCa, including it among the mechanisms of $\mathrm{PCa}$ cells/OB cross-talk essential to guide bone metastasis. More importantly, we provide a novel target to hinder or prevent bone dissemination, the major problem for PCa survival. Moreover, we would like to point out the umpteenth biological effect of MG-H1, namely that of driving de-differentiation, which was never reported before.

Finally, we found that patients with bone metastases presented significantly higher levels of MG-H1 than those with metastases to other organs. These in vivo results would support our mechanistic data and would seem to suggest a potential translational value of circulating MG-H1 as a bone metastases marker. Although further in vivo and epidemiologic studies are needed to prove this hypothesized translational value, our results would seem to head in this direction. Hence, in this regard, our results would open the way to additional studies aimed at investigating the putative role of MG-H1 circulating level as a biomarker of PCa osteotropism, useful to stratify PCa patient risk to develop bone metastases, which is fundamental to define personalized diagnostic and therapeutic strategies, possibly at the earliest stages of the disease. In fact, as mentioned above, the majority of patients with advanced PCa develop skeletal metastases, which may ultimately lead to serious complications, named "skeletal-related events" (SRE), that often dramatically impact on quality of life and survival. 


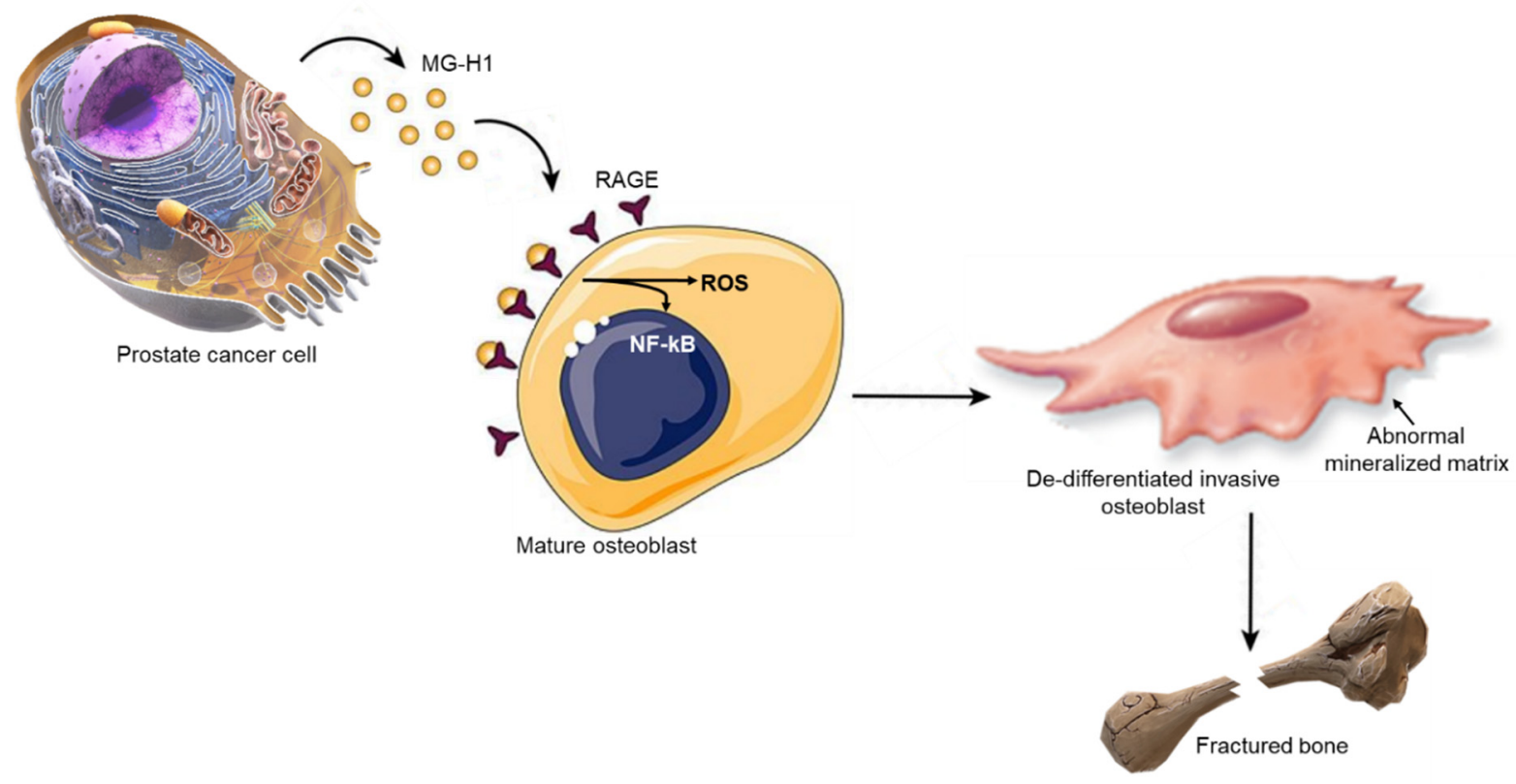

Figure 13. Metastatic prostate cancer (PCa) cells secrete methylglyoxal (MG)-derived 5-hydro-5-methylimidazolone (MG$\mathrm{H} 1)$ to reprogram human osteoblasts (OB) into a dedifferentiated, malignant-like phenotype: a possible novel player in prostate cancer bone metastases. MG-H1 released by PCa cells induces OB to dedifferentiate, assuming a spindle-shape morphology, reducing osteogenic differentiation markers, decreasing adhesive proteins, enhancing mesenchymal-like components and cell protrusions, acquiring motility properties. In addition, MG-H1 increased abnormal OB mineralization activity, leading to a bone structure with a markedly reduced mechanical strength and, consequently, more susceptible to pathological fractures. All these changes occurred via MG-H1 binding and activation of the receptor for advanced glycation end products (AGEs), RAGE. Hence, MG-H1 represents a novel player in the cross-talk between PCa cells and OB to create a favorable growth environment for bone metastases.

\section{Materials and Methods}

\subsection{Reagents}

All of the chemicals used in the present study were analytical grade reagents from various sources. Phosphate-buffered saline (PBS), formaldehyde acetic acid and ammonium hydroxide, aminoguanidine bicarbonate (AG), MTT [3-(4,5-dimethylthiazol-2-yl)-2,5diphenyltetrazolium bromide] and FPS-ZM1 were purchased from Merck Spa (Milan, Italy). Laemmli buffer and $2^{\prime}-7^{\prime}$-dichlorofluorescein-diacetate $\left(\mathrm{H}_{2} \mathrm{DCF}-\mathrm{DA}\right)$ were purchased by Thermo Fisher Scientific (Milan, Italy), Roti-Block from Prodotti Gianni (Milan, Italy), and bicinchoninic acid (BCA) kit from Thermo Fisher Scientific (Milan, Italy).

\subsection{Cell Cultures}

PC3, LNCaP, DU145, PNT2 cell lines were purchased by the American Type Culture Collection (ATCC) (Manassas, VA, USA) and cultured in RPMI medium supplemented with antimycotic and antibiotics (Thermo Fisher Scientific (Milan, Italy) at $37^{\circ} \mathrm{C}$ and $5 \%$ $\mathrm{CO}_{2}[23,48]$. Human primary osteoblasts (OB) were purchased from PromoCell (Heidelberg, Germany) and cultured in DMEM (Thermo Fisher Scientific (Milan, Italy) supplemented with $10 \%$ fetal calf serum (FCS, Thermo Fisher Scientific (Milan, Italy), antimycotic, and antibiotics (Thermo Fisher Scientific, Milan, Italy) [14].

\subsection{Preparation of Conditioned Medium (CM) and Treatments}

Cells were grown in $25 \mathrm{~cm}^{2}$ tissue culture flasks with their respective maintenance medium until they reached $90 \%$ confluence. Then, the medium was replaced with $10 \mathrm{~mL}$ of medium containing $0.5 \%$ charcoal-stripped FBS and continued to be cultured for $48 \mathrm{~h}$. Supernatants were collected as CM. OB were cultured in CM for 6 and $24 \mathrm{~h}$. OB cultured for the same period of time in their specific growth medium represented control cells 
(CTR). AG and FPS-ZM1 were prepared as stock solutions and diluted to the desired final concentrations immediately before use. The final concentrations of the compounds were as follows: AG (1 mM, for $6 \mathrm{~h}$ ) and FPS-ZM1 (100 nM, 10 h). For DMSO-solubilized FPS-ZM1, the final DMSO concentration in incubations was $0.01 \%$. Controls contained an identical volume of DMSO vehicles.

\subsection{MG-H1 Detection}

MG-H1 was measured either by the OxiSelectTM methylglyoxal competitive enzymelinked immunosorbent assay (ELISA) kit (DBA Italia Srl, Segrate, Italy) according to the manufacturer's instructions or by western blot using the anti-MG-H1 Ab (dilution 1:1000, Cell Biolabs, cat. \# STA-011, DBA Italia Srl, Segrate, Italy).

\subsection{Cell Lysis and Western Blot}

Cells were lysed in radioimmunoprecipitation assay (RIPA) lysis buffer to extract total proteins $[49,50]$. Nuclear extracts were obtained using the FractionPREP Cell Fractionation kit (Biovision, Vinci-Biochem, Florence, Italy) according to the manufacturer's instructions $[49,50]$. Western blot was performed with an equal protein concentration $(40 \mu \mathrm{g})$ of samples in Laemmli buffer. After boiling them for $5 \mathrm{~min}$, they were resolved on $10 \%, 12 \%$, or $15 \%$ SDS-PAGE and blotted onto a nitrocellulose membrane with iBlot Dry Blotting System (Invitrogen, Milan, Italy). Non-specific binding sites were blocked in Roti-Block at room temperature for $1 \mathrm{~h}$. Membranes were then incubated overnight at $4{ }^{\circ} \mathrm{C}$ with an appropriate dilution of the following primary specific Abs: mouse anti-MG-H1 $\mathrm{mAb}$ (dilution 1:1000, Cell Biolabs, cat. \# STA-011, DBA Italia Srl, Segrate, Italy), mouse anti-RAGE (A-9) mAb (dilution 1:1000, Santa Cruz, cat. \# sc-365154, DBA Italia Srl, Segrate, Italy), rabbit anti-NFkB p65 (D14E12) mAb (dilution 1:1000, cat. \# 8242, Cell Signaling Technology, Milan, Italy), mouse anti- $\beta$-actin mAb (dilution 1:1000, Santa Cruz, cat. \# sc47778, DBA Italia Srl, Segrate, Italy) and mouse anti-lamin B1 mAb (A-11) (dilution 1:1000, Santa Cruz, cat. \# sc- 377000, DBA Italia Srl, Milan, Italy). Membranes were subsequently incubated with the appropriate HRP-conjugated secondary $\mathrm{Ab}$ at room temperature for $1 \mathrm{~h}$ to detect antigen-antibody complexes, and ECL was used as a revealing system (Amersham Pharmacia, Milan, Italy). The membranes were then appropriately re-probed with $\beta$-actin or lamin B1 as internal loading controls.

\subsection{Cell Viability and Morphology}

Cell viability was evaluated by MTT assay [14], while cell morphology by means of phase-contrast microscopy [14].

4.7. RNA Isolation, Reverse Transcription, and Real-Time Reverse Transcriptase-Polymerase Chain Reaction (RT-PCR) Analyses

TRIzol reagent (Thermo Fisher Scientific, Milan, Italy) was employed to isolate total cellular RNA. A total of $1 \mu \mathrm{g}$ of RNA was used to synthesize cDNA using RevertAid ${ }^{\mathrm{TM}}$ H Minus First Strand cDNA Synthesis Kit (Thermo Fisher Scientific, Milan, Italy). Gene expression versus $\beta$-actin was evaluated by RT-PCR on an MX3000P Real-Time PCR System (Agilent Technology, Milan, Italy). The sequences of the oligonucleotide primers are reported in Table 1. PCR reactions were performed in a total volume of $20 \mu \mathrm{L}$ with 25 ng of cDNA, 1 X Brilliant II SYBR ${ }^{\circledR}$ Green QPCR Master Mix, ROX Reference Dye, and $600 \mathrm{nM}$ of specific primers. The thermal cycling conditions were 1 cycle at $95^{\circ} \mathrm{C}$ for $5 \mathrm{~min}$ followed by 45 cycles at $95^{\circ} \mathrm{C}$ for $20 \mathrm{~s}$ and $60^{\circ} \mathrm{C}$ for $30 \mathrm{~s}$. Melting curves were performed for all of the primer pairs in standard conditions. Comparative analysis of gene expression was performed by means of the $2-(\Delta \Delta C T)$ method [51,52]. 
Table 1. Primers for qRT-PCR.

\begin{tabular}{|c|c|c|}
\hline Gene & Forward Primer $\left(5^{\prime}-3^{\prime}\right)$ & Reverse Primer $\left(5^{\prime}-3^{\prime}\right)$ \\
\hline VIM & GCACACAGCAAGGCGATGG & GGAGCGAGAGTGGCAGAGG \\
\hline$\alpha-S M A$ & GGCATCATCACCAACTGGGACGAC & AGCACCGCCTGGATAGCCACATAC \\
\hline TGF- $\beta 1$ & GGCGACCCACAGAGAGGAAATAG & AGGCAGAAATTGGCGTGGTAGC \\
\hline CDH11 & TGGCAGCAAGTATCCAATGG & TTTGGTTACGTGGTAGGCAC \\
\hline ITGB1 & TGATTGGCTGGAGGAATGTTA & GTTTCTGGACAAGGTGAGCAA \\
\hline ITGA3 & GGACCTTACAACGCCGAGTG & GGAGGCTCTTTGGCTTGTTTT \\
\hline Runx2 & GCTCTTCCCAAAGCCAGAGT & ATCCTGAC-GAAGTGCCAT \\
\hline $\operatorname{Col} 1 \alpha 1$ & GAGGGCCAAGACGAAGACATC & CAGATCACGTCATCGCACAAC \\
\hline $\mathrm{ON}$ & CCTGGAGACAAGGTGCTAACAT & CGAGTTCTCAGCCTGTGAGA \\
\hline OSX & CСАССТАСССАТСТGACT & GTTTGGCTCCACCACTCC \\
\hline CD44 & AGTCCCTGGATCACCGA & CCTCTTGGTTGCTGTCTCA \\
\hline FASC & CTGGCTACACGCTGGAGTTC & CTGAGTCCCCTGCTGTCTCC \\
\hline PFN1 & TGGAGCAAACCCTACCCTT & AGCCCAGACACCGAACTTT \\
\hline COFN & ATGCССТСТATGATGCAACC & GCTTGATCCCTGTCAGCTTC \\
\hline RADX & GAATCAGGAGCAGCTAGCAGCAGAACTT & TTGGTCTTTTCCAAGTCTTCCTGGGCTGCA \\
\hline $\mathrm{OC}$ & TCACACTCCTCGCCCTATTGG & TCACACTCCTCGCCCTATTGG \\
\hline OP & AGACCCCAAAAGTAAGGAAGAAG & GACAACCGTGGGAAAACAAATAAG \\
\hline Glo1 & СTCTCCAGAAAAGCTACACTTTGAG & CGAGGGTCTGAATTGCCATTG \\
\hline$\beta$-actin & САСТСТTССАGССТTССТTСС & ACAGCACTGTGTTGGCGTAC \\
\hline
\end{tabular}

\subsection{Migration, Invasion and Cell Counting Assays}

Migration was evaluated by the CytoSelect 24-Well Cell Migration Assay kit (cat. \# CBA-100-5, DBA Italia S.r.l., Milan, Italy) and invasion by the CytoSelect 24-Well Cell Invasion Assay kit (cat. \# CBA-110, DBA Italia S.r.l., Milan, Italy), according to the manufacturer's instructions. Cell counting was performed using trypan blue (Thermo Fisher Scientific, Milan, Italy) [48].

\subsection{Glo1-Specific Enzyme Activity}

Glo1-specific enzyme activity was assessed as previously described [53]. Briefly, the assay solution contained $0.1 \mathrm{M}$ sodium phosphate buffer (pH 7.2), $2 \mathrm{mM} \mathrm{MG}$, and $1 \mathrm{mM}$ GSH. The reaction was monitored spectrophotometrically by following the increase in absorbance at $240 \mathrm{~nm}$ and $25^{\circ} \mathrm{C}$. One unit of enzyme activity was defined as $1 \mu \mathrm{mol}$ of S-d-lactoylglutathione produced per minute. To calculate Glo1-specific enzyme activity (s.a.), enzyme activity was related to the total protein concentration, determined by BCA.

\subsection{Alizarin Red Staining}

Alizarin red staining was performed with the Alizarin Red S Staining Quantification Assay (ARed-Q, cat. \#867, ScienCell Research Laboratories, Rome, Italy) to evaluate calcium deposition. Briefly, cells were washed with PBS three times, fixed with $4 \%$ formaldehyde for $15 \mathrm{~min}$ at room temperature, washed with distilled water, and stained with $40 \mathrm{mM}$ Alizarin red S for $30 \mathrm{~min}$. Then, the dye was eluted using $10 \%$ acetic acid for $30 \mathrm{~min}$ at room temperature, neutralized with $10 \%$ ammonium hydroxide, and the absorbance was measured at $405 \mathrm{~nm}$ in a microplate reader. 


\subsection{Reactive Oxidative Species (ROS) Measurement}

Assessment of ROS cellular levels, including levels of general reactive oxygen species and reactive nitrogen species, was performed as previously described [49,50], using the membranepermeable $2^{\prime}, 7^{\prime}$-dichlorodihydrofluorescein diacetate $\left(\mathrm{H}_{2} \mathrm{DCF}-\mathrm{DA}\right)$ fluorogenic dye.

\subsection{Circulating Levels of MG-H1 in Samples from Metastasis-bearing Patients}

OxiSelectTM Methylglyoxal Competitive ELISA kit (DBA Italia Srl, Segrate, Italy) was used to detect MG-H1 levels in lymphocytes from bone metastasis-bearing patients $(n=20)$ and patients with other metastases $(n=10)$. The study was conducted on residual material from patients previously enrolled for another study [54]. At the time of sampling (2005-2006), as part of the internal hospital protocol, oral informed consent from patients was routinely obtained. In this phase, among other clinical aspects, the patients were informed that part of the samples (blood samples) might have been used for research purposes without undermining the clinical/diagnostic analyses. Moreover, access to the data of patients and biological material had already been fully anonymized before the authors accessed them. Finally, observation of all rules concerning confidentiality and protection of personal data, in accordance with European Union, international, and national rules, was respected. The research has been carried out in accordance with the Declaration of Helsinki and guidelines of the Santa Maria of Misericordia Hospital of Perugia.

\subsection{Statistical Analysis}

Results were expressed as means \pm standard deviation (SD) of three independent experiments. One-way analysis of variance with Dunnett's correction was employed to determine differences among groups. Statistical significance was set at $p<0.05$.

\section{Conclusions}

In summary, we demonstrated that the paracrine release of MG-H1 by osteotropic $\mathrm{PCa}$ cells reprograms $\mathrm{OB}$, very likely to make them create a unique microenvironment to allow disseminating PCa cells to grow and flourish. Our data further improve our knowledge of the complex mechanisms underpinning PCa bone metastases onset and open the way to additional in vivo research aimed at studying novel therapeutic strategies, interfering with $\mathrm{PCa} / \mathrm{OB}$ cross-talk in order to impair PCa metastases, improve patient quality of life, and, more important, reduce morbidity and increase survival. Of note, since bone is one of the most common metastatic sites for other malignancies $[55,56]$, this research also sets the stage for additional studies aimed at investigating MG-H1 role in bone-metastatic responses and malignant behaviors in broader cancer contexts.

Supplementary Materials: The following are available online at https:/ /www.mdpi.com/article/10 .3390/ijms221910191/s1.

Author Contributions: Conceptualization, C.A.; methodology, L.M. (Lorella Marinucci), R.F. and C.A.; formal analysis, C.A. and L.M. (Lorella Marinucci); data curation, C.A.; writing-original draft preparation, C.A.; writing - review and editing, C.A., L.M. (Lorella Marinucci), L.M. (Lara Macchioni) and V.N.T.; funding acquisition, C.A. and V.N.T. All authors have read and agreed to the published version of the manuscript.

Funding: This research and the APC were funded by the University of Perugia (RB2019CANT) (local research grants 2019 to CA).

Institutional Review Board Statement: The research has been carried out in accordance with the Declaration of Helsinki and in line with the general guidelines of the Santa Maria of Misericordia Hospital of Perugia.

Informed Consent Statement: Oral informed consent was obtained from all subjects involved in the study.

Data Availability Statement: The data presented in this study are available on request from the corresponding author. 
Conflicts of Interest: The authors declare no conflict of interest.

\section{References}

1. Rucci, N.; Teti, A. Osteomimicry: How the Seed Grows in the Soil. Calcif. Tissue Int. 2017, 102, 131-140. [CrossRef] [PubMed]

2. Bonollo, F.; Thalmann, G.N.; Julio, M.K.-D.; Karkampouna, S. The Role of Cancer-Associated Fibroblasts in Prostate Cancer Tumorigenesis. Cancers 2020, 12, 1887. [CrossRef] [PubMed]

3. Paget, S. The distribution of secondary growths in cancer of the breast. Cancer Metastasis Rev. 1989, 8, 98-101. [CrossRef]

4. Bussard, K.; Gay, C.V.; Mastro, A.M. The bone microenvironment in metastasis; what is special about bone? Cancer Metastasis Rev. 2007, 27, 41-55. [CrossRef] [PubMed]

5. Shupp, A.B.; Kolb, A.D.; Mukhopadhyay, D.; Bussard, K.M. Cancer Metastases to Bone: Concepts, Mechanisms, and Interactions with Bone Osteoblasts. Cancers 2018, 10, 182. [CrossRef]

6. Quiroz-Munoz, M.; Izadmehr, S.; Arumugam, D.; Wong, B.; Kirschenbaum, A.; Levine, A.C. Mechanisms of Osteoblastic Bone Metastasis in Prostate Cancer: Role of Prostatic Acid Phosphatase. J. Endocr. Soc. 2019, 3, 655-664. [CrossRef]

7. Keller, E.T.; Zhang, J.; Cooper, C.R.; Smith, P.C.; McCauley, L.K.; Pienta, K.; Taichman, R.S. Prostate Carcinoma Skeletal Metastases: Cross-talk between Tumor and Bone. Cancer Metastasis Rev. 2001, 20, 333-349. [CrossRef]

8. Ottewell, P.D. The role of osteoblasts in bone metastasis. J. Bone Oncol. 2016, 5, 124-127. [CrossRef]

9. Koeneman, K.S.; Yeung, F.; Chung, L.W.K. Osteomimetic properties of prostate cancer cells: A hypothesis supporting the predilection of prostate cancer metastasis and growth in the bone environment. Prostate 1999, 39, 246-261. [CrossRef]

10. Carducci, M.A.; Nelson, J.B.; Bowling, M.K.; Rogers, T.; Eisenberger, M.A.; Sinibaldi, V.; Donehower, R.; Leahy, T.L.; Carr, R.A.; Isaacson, J.D.; et al. Atrasentan, an Endothelin-Receptor Antagonist for Refractory Adenocarcinomas: Safety and Pharmacokinetics. J. Clin. Oncol. 2002, 20, 2171-2180. [CrossRef]

11. Carducci, M.A.; Padley, R.J.; Breul, J.; Vogelzang, N.J.; Zonnenberg, B.A.; Daliani, D.D.; Schulman, C.C.; Nabulsi, A.A.; Humerickhouse, R.A.; Weinberg, M.A.; et al. Effect of Endothelin-A Receptor Blockade with Atrasentan on Tumor Progression in Men With Hormone-Refractory Prostate Cancer: A Randomized, Phase II, Placebo-Controlled Trial. J. Clin. Oncol. 2003, 21, 679-689. [CrossRef] [PubMed]

12. Quinn, D.I.; Tangen, C.M.; Hussain, M.; Lara, P.N.; Goldkorn, A.; Moinpour, C.M.; Garzotto, M.G.; Mack, P.C.; Carducci, M.A.; Monk, J.P.; et al. Docetaxel and atrasentan versus docetaxel and placebo for men with advanced castration-resistant prostate cancer (SWOG S0421): A randomised phase 3 trial. Lancet Oncol. 2013, 14, 893-900. [CrossRef]

13. Antognelli, C.; Talesa, V.N. Glyoxalases in Urological Malignancies. Int. J. Mol. Sci. 2018, 19, 415. [CrossRef]

14. Marinucci, L.; Balloni, S.; Fettucciari, K.; Bodo, M.; Talesa, V.N.; Antognelli, C. Nicotine induces apoptosis in human osteoblasts via a novel mechanism driven by $\mathrm{H} 2 \mathrm{O} 2$ and entailing Glyoxalase 1-dependent MG-H1 accumulation leading to TG2-mediated NF-kB desensitization: Implication for smokers-related osteoporosis. Free Radic. Biol. Med. 2018, 117, 6-17. [CrossRef] [PubMed]

15. Xue, J.; Ray, R.; Singer, D.; Böhme, D.; Burz, D.S.; Rai, V.; Hoffmann, R.; Shekhtman, A. The Receptor for Advanced Glycation End Products (RAGE) Specifically Recognizes Methylglyoxal-Derived AGEs. Biochemistry 2014, 53, 3327-3335. [CrossRef] [PubMed]

16. Ott, C.; Jacobs, K.; Haucke, E.; Santos, A.N.; Grune, T.; Simm, A. Role of advanced glycation end products in cellular signaling. Redox Biol. 2014, 2, 411-429. [CrossRef] [PubMed]

17. Jeong, S.-R.; Lee, K.-W. Methylglyoxal-Derived Advanced Glycation End Product (AGE4)-Induced Apoptosis Leads to Mitochondrial Dysfunction and Endoplasmic Reticulum Stress through the RAGE/JNK Pathway in Kidney Cells. Int. J. Mol. Sci. 2021, 22, 6530. [CrossRef] [PubMed]

18. Suh, K.S.; Chon, S.; Choi, E.M. Protective effects of honokiol against methylglyoxal-induced osteoblast damage. Chem. Interact. 2016, 244, 169-177. [CrossRef]

19. Franke, S.; Rüster, C.; Pester, J.; Hofmann, G.; Oelzner, P.; Wolf, G. Advanced glycation end products affect growth and function of osteoblasts. Clin. Exp. Rheumatol. 2011, 29, 650-660.

20. Antognelli, C.; Mezzasoma, L.; Fettucciari, K.; Talesa, V.N. A novel mechanism of methylglyoxal cytotoxicity in prostate cancer cells. Int. J. Biochem. Cell Biol. 2013, 45, 836-844. [CrossRef] [PubMed]

21. Antognelli, C.; Mezzasoma, L.; Fettucciari, K.; Mearini, E.; Talesa, V.N. Role of glyoxalase I in the proliferation and apoptosis control of human LNCaP and PC3 prostate cancer cells. Prostate 2013, 73, 121-132. [CrossRef] [PubMed]

22. Talesa, V.N.; Ferri, I.; Bellezza, G.; Love, H.D.; Sidoni, A.; Antognelli, C. Glyoxalase 2 Is Involved in Human Prostate Cancer Progression as Part of a Mechanism Driven By PTEN/PI3K/AKT/mTOR Signaling with Involvement of PKM2 and ER $\alpha$. Prostate 2017, 77, 196-210. [CrossRef] [PubMed]

23. Antognelli, C.; Cecchetti, R.; Riuzzi, F.; Peirce, M.J.; Talesa, V.N. Glyoxalase 1 sustains the metastatic phenotype of prostate cancer cells via EMT control. J. Cell. Mol. Med. 2018, 22, 2865-2883. [CrossRef]

24. Antognelli, C.; Mandarano, M.; Prosperi, E.; Sidoni, A.; Talesa, V. Glyoxalase-1-Dependent Methylglyoxal Depletion Sustains PD-L1 Expression in Metastatic Prostate Cancer Cells: A Novel Mechanism in Cancer Immunosurveillance Escape and a Potential Novel Target to Overcome PD-L1 Blockade Resistance. Cancers 2021, 13, 2965. [CrossRef] [PubMed]

25. Kwon, O.K.; Jeon, J.M.; Sung, E.; Na, A.-Y.; Kim, S.J.; Lee, S. Comparative Secretome Profiling and Mutant Protein Identification in Metastatic Prostate Cancer Cells by Quantitative Mass Spectrometry-based Proteomics. Cancer Genom.-Proteom. 2018, 15, 279-290. [CrossRef] 
26. Bear, J.E.; Haugh, J.M. Directed migration of mesenchymal cells: Where signaling and the cytoskeleton meet. Curr. Opin. Cell Biol. 2014, 30, 74-82. [CrossRef]

27. Schroeder, M.E.; Rodriguez, A.G.; Speckl, K.F.; Walker, C.J.; Midekssa, F.S.; Grim, J.C.; Weiss, R.M.; Anseth, K.S. Collagen networks within 3D PEG hydrogels support valvular interstitial cell matrix mineralization. Acta Biomater. 2021, 119, 197-210. [CrossRef]

28. Kinner, B.; Spector, M. Expression of smooth muscle actin in osteoblasts in human bone. J. Orthop. Res. 2002, 20, 622-632. [CrossRef]

29. Torii, Y.; Hitomi, K.; Tsukagoshi, N. Synergistic effect of BMP-2 and ascorbate on the phenotypic expression of osteoblastic MC3T3-E1 cells. Mol. Cell. Biochem. 1996, 165, 25-29. [CrossRef]

30. Bonneau, C.; Eliès, A.; Kieffer, Y.; Bourachot, B.; Ladoire, S.; Pelon, F.; Hequet, D.; Guinebretière, J.-M.; Blanchet, C.; VincentSalomon, A.; et al. A subset of activated fibroblasts is associated with distant relapse in early luminal breast cancer. Breast Cancer Res. 2020, 22, 1-22. [CrossRef] [PubMed]

31. Brunner, M.; Mandier, N.; Gautier, T.; Chevalier, G.; Ribba, A.-S.; Guardiola, P.; Block, M.R.; Bouvard, D. $\beta 1$ integrins mediate the BMP2 dependent transcriptional control of osteoblast differentiation and osteogenesis. PLoS ONE 2018, 13, e0196021. [CrossRef]

32. Gioia, M.; Michaletti, A.; Scimeca, M.; Marini, M.; Tarantino, U.; Zolla, L.; Coletta, M. Simulated microgravity induces a cellular regression of the mature phenotype in human primary osteoblasts. Cell Death Discov. 2018, 4, 59. [CrossRef]

33. Molagoda, I.M.N.; Karunarathne, W.A.H.M.; Choi, Y.H.; Park, E.K.; Jeon, Y.-J.; Lee, B.-J.; Kang, C.-H.; Kim, G.-Y. Fermented Oyster Extract Promotes Osteoblast Differentiation by Activating the Wnt/ $\beta$-Catenin Signaling Pathway, Leading to Bone Formation. Biomolecules 2019, 9, 711. [CrossRef]

34. Morath, I.; Hartmann, T.N.; Orian-Rousseau, V. CD44: More than a mere stem cell marker. Int. J. Biochem. Cell Biol. 2016, 81, 166-173. [CrossRef]

35. Shi, G.; Yang, F. Krüppel-like factor 1 (KLF1) promoted the proliferation, migration and invasion of human lens epithelial cells by enhancing the expression of Zinc Finger and BTB Domain Containing 7A (ZBTB7A) and activating Wnt/ $\beta$-catenin pathway. Bioengineered 2021, 12, 4374-4384. [CrossRef] [PubMed]

36. Lin, W.; Ezura, Y.; Izu, Y.; Aryal, S.A.C.; Kawasaki, M.; Chantida, P.N.M.; Moriyama, K.; Noda, M.; Smriti, A.; Pawaputanon, C. Profilin Expression Is Regulated by Bone Morphogenetic Protein (BMP) in Osteoblastic Cells. J. Cell. Biochem. 2015, 117, 621-628. [CrossRef] [PubMed]

37. Zhu, Y.; Gu, Y.; Jiang, C.; Chen, L. Osteonectin regulates the extracellular matrix mineralization of osteoblasts through P38 signaling pathway. J. Cell. Physiol. 2020, 235, 2220-2231. [CrossRef]

38. White, K.; Chalaby, R.; Lowe, G.; Berlin, J.; Glackin, C.; Olabisi, R. Calcein Binding to Assess Mineralization in Hydrogel Microspheres. Polymers 2021, 13, 2274. [CrossRef] [PubMed]

39. Cumming, A.P.; Hopmans, S.N.; Vukmirović-Popović, S.; Duivenvoorden, W.C. PSA affects prostate cancer cell invasion in vitro and induces an osteoblastic phenotype in bone in vivo. Prostate Cancer Prostatic Dis. 2011, 14, 286-294. [CrossRef]

40. Wu, L.; Xiang, S.; Hu, X.; Mo, M.; Zhao, C.; Cai, Y.; Tong, S.; Jiang, H.; Chen, L.; Wang, Z.; et al. Prostate-specific antigen modulates the osteogenic differentiation of MSCs via the cadherin 11-Akt axis. Clin. Transl. Med. 2020, 10, 363-373. [CrossRef] [PubMed]

41. Viryasova, G.; Golenkina, E.; Hianik, T.; Soshnikova, N.; Dolinnaya, N.; Gaponova, T.; Romanova, Y.; Sud'Ina, G. Magic Peptide: Unique Properties of the LRR11 Peptide in the Activation of Leukotriene Synthesis in Human Neutrophils. Int. J. Mol. Sci. 2021, 22, 2671. [CrossRef]

42. Mao, Y.X.; Cai, W.J.; Sun, X.Y.; Dai, P.P.; Li, X.M.; Wang, Q.; Huang, X.L.; He, B.; Wang, P.P.; Wu, G.; et al. RAGE-dependent mitochondria pathway: A novel target of silibinin against apoptosis of osteoblastic cells induced by advanced glycation end products. Cell Death Dis. 2018, 9, 1-14. [CrossRef] [PubMed]

43. Hinz, N.; Jücker, M. AKT in Bone Metastasis of Solid Tumors: A Comprehensive Review. Cancers 2021, 13, 2287. [CrossRef] [PubMed]

44. Ma, X.; Yu, J. Role of the bone microenvironment in bone metastasis of malignant tumors-Therapeutic implications. Cell. Oncol. 2020, 43, 751-761. [CrossRef] [PubMed]

45. Kessel, K.; Bernemann, C.; Bögemann, M.; Rahbar, K. Evolving Castration Resistance and Prostate Specific Membrane Antigen Expression: Implications for Patient Management. Cancers 2021, 13, 3556. [CrossRef] [PubMed]

46. Stewart, S.; Gomez, A.W.; Armstrong, B.E.; Henner, A.; Stankunas, K. Sequential and Opposing Activities of Wnt and BMP Coordinate Zebrafish Bone Regeneration. Cell Rep. 2014, 6, 482-498. [CrossRef]

47. Almeida, M.; Han, L.; Martin-Millan, M.; O’Brien, C.A.; Manolagas, S.C. Oxidative Stress Antagonizes Wnt Signaling in Osteoblast Precursors by Diverting $\beta$-Catenin from T Cell Factor- to Forkhead Box O-mediated Transcription. J. Biol. Chem. 2007, 282, 27298-27305. [CrossRef]

48. Antognelli, C.; Ferri, I.; Bellezza, G.; Siccu, P.; Love, H.D.; Talesa, V.N.; Sidoni, A. Glyoxalase 2 drives tumorigenesis in human prostate cells in a mechanism involving androgen receptor and p53-p21 axis. Mol. Carcinog. 2017, 56, 2112-2126. [CrossRef]

49. Antognelli, C.; Trapani, E.; Monache, S.D.; Perrelli, A.; Daga, M.; Pizzimenti, S.; Barrera, G.; Cassoni, P.; Angelucci, A.; Trabalzini, L.; et al. KRIT1 loss-of-function induces a chronic Nrf2-mediated adaptive homeostasis that sensitizes cells to oxidative stress: Implication for Cerebral Cavernous Malformation disease. Free Radic. Biol. Med. 2018, 115, 202-218. [CrossRef] 
50. Antognelli, C.; Trapani, E.; Monache, S.D.; Perrelli, A.; Fornelli, C.; Retta, F.; Cassoni, P.; Talesa, V.N.; Retta, S.F. Data in support of sustained upregulation of adaptive redox homeostasis mechanisms caused by KRIT1 loss-of-function. Data Brief 2018, 16, 929-938. [CrossRef]

51. Monache, S.D.; Pulcini, F.; Frosini, R.; Mattei, V.; Talesa, V.; Antognelli, C. Methylglyoxal-Dependent Glycative Stress Is Prevented by the Natural Antioxidant Oleuropein in Human Dental Pulp Stem Cells through Nrf2/Glo1 Pathway. Antioxidants 2021, 10, 716. [CrossRef] [PubMed]

52. Antognelli, C.; Frosini, R.; Santolla, M.F.; Peirce, M.J.; Talesa, V.N. Oleuropein-Induced Apoptosis Is Mediated by Mitochondrial Glyoxalase 2 in NSCLC A549 Cells: A Mechanistic Inside and a Possible Novel Nonenzymatic Role for an Ancient Enzyme. Oxidative Med. Cell. Longev. 2019, 2019, 8576961. [CrossRef] [PubMed]

53. Antognelli, C.; Mancuso, F.; Frosini, R.; Arato, I.; Calvitti, M.; Calafiore, R.; Talesa, V.N.; Luca, G. Testosterone and Follicle Stimulating Hormone-Dependent Glyoxalase 1 Up-Regulation Sustains the Viability of Porcine Sertoli Cells through the Control of Hydroimidazolone- and Argpyrimidine-Mediated NF-кB Pathway. Am. J. Pathol. 2018, 188, 2553-2563. [CrossRef] [PubMed]

54. Antognelli, C.; Mezzasoma, L.; Mearini, E.; Talesa, V.N. Glyoxalase 1-419C>A Variant Is Associated with Oxidative Stress: Implications in Prostate Cancer Progression. PLoS ONE 2013, 8, e74014. [CrossRef] [PubMed]

55. Wang, M.; Xia, F.; Wei, Y.; Wei, X. Molecular mechanisms and clinical management of cancer bone metastasis. Bone Res. 2020, 8 , 1-20. [CrossRef] [PubMed]

56. Kreps, L.; Addison, C. Targeting Intercellular Communication in the Bone Microenvironment to Prevent Disseminated Tumor Cell Escape from Dormancy and Bone Metastatic Tumor Growth. Int. J. Mol. Sci. 2021, 22, 2911. [CrossRef] 